Discussion Papers of the

Max Planck Institute for

Research on Collective Goods

2021/6

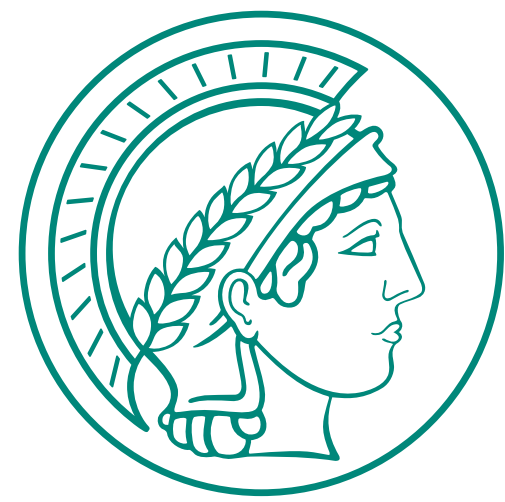

Income Risk, Precautionary Saving, and Loss Aversion

- An Empirical Test

Marcela Ibanez

Sebastian 0. Schneider 


\title{
Income Risk, Precautionary Saving, and Loss Aversion - An Empirical Test
}

\author{
Marcela Ibanez / Sebastian 0. Schneider
}

March 2021 


\title{
Income Risk, Precautionary Saving, and Loss Aversion - An Empirical Test ${ }^{*}$
}

\author{
Marcela Ibanez \\ marcela.ibanez@zentr.uni-goettingen.de \\ University of Goettingen, Germany
}

\author{
Sebastian O. Schneider \\ sschneider@coll.mpg.de \\ Max Planck Institute for Research on Collective \\ Goods, Bonn, Germany
}

March 3, 2021

\begin{abstract}
This paper empirically examines the behavioral precautionary saving hypothesis by Kôszegi and Rabin (2009) stating that uncertainty about future income triggers saving because of loss aversion. We extend their theoretical analysis to also consider the internal margin, i.e., the strength, of loss aversion, and empirically study the relation between income risk, experimentally elicited loss aversion and precautionary savings. We do so using a sample of 640 individuals from the low-income population of Bogotá, characterized by limited financial education and subject to substantial income risk. In line with the theoretical predictions, we find that an increase in income risk is associated with higher savings for loss-averse individuals, and that this increase in savings grows with the degree of loss aversion. Thus, as suggested by Kôszegi and Rabin (2009), but contrarily to common assumptions, our findings establish that loss aversion is not necessarily an obstacle to saving, and thus identify new approaches of increasing saving among individuals with low financial education.
\end{abstract}

JEL-classification: D11, D14, D15, D81, D90, G40, J65, O16

Keywords: Reference-dependent utility, expectations, consumption plans, precautionary savings, loss aversion, risk preferences, income risk, low-income, Bogotá, experiment.

${ }^{*}$ We thank Zvonimir Bašić, Claudia Cerrone, Sanjit Dhami, Christoph Engel, Stephan Klasen, Katja Michaelowa and Matthias Sutter, as well as participants at the Behavioral Finance Working Group Conference in London, the Symposium on Economic Experiments in Developing Countries in Kenya and the European ESA meeting in Bergen for helpful comments and suggestions. We thank Margarita Cabra, Lukas Hermann and Sonia Triviño for research assistance. Schneider gratefully acknowledges the financial support provided by the German Research Foundation (DFG) via RTG 1723 and the Foundation of German Businesses (sdw). 


\section{Introduction}

Loss aversion has typically been associated with poor financial status and poor financial decisionmaking - both theoretically and empirically (e.g., Benartzi and Thaler, 1995; Odean, 1998; Thaler and Benartzi, 2004; Cardenas and Carpenter, 2013; Barberis, 2013). However, in the reference-dependent model of inter-temporal consumption by Köszegi and Rabin (2009), loss aversion takes a diametrically opposed role: Individuals who are loss averse with respect to expected future consumption save more today when facing income risk, in order to decrease the utility loss associated with possible consumption levels below their expectations. ${ }^{1}$ Yet, there is no empirical test of this loss aversion-based precautionary motive for savings.

In this paper, we extend the analysis of the model by Köszegi and Rabin (2009), derive and test three specific hypotheses: i) loss-averse individuals hold higher savings when exposed to greater income risk (precautionary saving motive), ii) holding (positive) income risk constant, a higher degree of loss aversion implies more saving compared to lower degrees of loss aversion, and iii) the more loss averse individuals are, the higher the increase in saving associated with an increase in income risk. Using real-world data on savings and income risk and experimentally elicited, incentivized measures of loss aversion, we examine the relationship between income uncertainty, loss aversion, and savings empirically. This is the first paper that addresses the proposed theoretical relation empirically, and the first to investigate the relationship between household saving and loss aversion using a direct measure of loss aversion at the individual level.

The topic is important not only from a decision-theoretic perspective but also from a policy point of view. Saving rates are notoriously low in developing and developed nations alike (e.g., World Bank, 2014), resulting in a widespread inability to cope with income shocks. For example, in the U.S., nearly $40 \%$ of the population cannot easily come up with $\$ 400$ to cover unexpected expenses, and $25 \%$ of adults skipped medical treatments due to an inability to pay (Federal Reserve Board, 2020). Income shocks, and consequently the unpreparedness to cope with them, have serious negative impacts such as poor mental health and increased suicide rates (e.g., Clark et al., 2016; Christian et al., 2019). This calls for a an improvement in the savings situation especially for those facing limitations in access to credit markets and weak social protection

\footnotetext{
${ }^{1}$ Following Köszegi and Rabin (2009) we use the terms income uncertainty and income risk as synonyms in this paper.
} 
systems. For them, savings are one of the few alternatives - if not the only one - to prepare for, and mitigate the effect of, income shocks (Dercon, 2010; Tovar and Urrutia, 2017). Yet, a prerequisite to improving this situation is understanding household saving behavior and its drivers. In this respect, the combined effect of income uncertainty and loss aversion has been completely neglected so far in empirical work.

We study the derived hypotheses focusing on the low-income population in Bogotá, Colombia. Although the financial means to save are certainly lower in this population group than in the middle-income class, we observe considerable heterogeneity in savings in our sample, implying that many individuals do engage in saving even though they are poor. ${ }^{2}$ What is more important, however, is that this population group is exposed to substantial income uncertainty, similar to comparable population groups in other developing countries (Loayza et al., 2009; Stampini et al., 2016). The majority of the employed population in our sample depends on informal employment $(52 \%)$ or are underemployed $(30 \%)$. Yet, informal risk sharing networks that are commonly observed in rural areas (e.g., D'Exelle and Verschoor, 2015) only play a minor role in poor, urban settings. Hence, due to its exposure to various income shocks without (formal and informal) social security systems in place, this population group is ideally suited to investigate the precautionary savings motive emerging from the reference-dependent model of consumption and saving by Köszegi and Rabin (2009). Moreover, since income shocks may pose a threat of falling into a poverty trap, they might be particularly consequential. Thus, the prospect of reducing future consumption can induce a severe loss in utility and thus, generate a strong incentive to save.

We construct a measure of savings as the total value of liquid assets. To measure loss aversion and risk preferences, we use the experimental method by Abdellaoui et al. (2007). To measure income risk, we use the official regional unemployment rate and the average perceived regional unemployment risk. We selected those measures as from the individual perspective, they can arguably be considered exogenous.

We find, in line with the precautionary savings motive resulting from the reference-dependent model of inter-temporal consumption by Kôszegi and Rabin (2009) that loss-averse individuals

\footnotetext{
${ }^{2}$ Several studies from development settings report similar findings, see, e.g., the review in Karlan et al. (2014).
} 
save more when they are exposed to greater income risk (Hypothesis 1). Similarly, controlling for income risk, more loss-averse individuals hold higher savings than less loss-averse individuals (Hypothesis 2). Moreover, the larger the degree of loss aversion, the larger the increase in savings associated with an increase in income risk (Hypothesis 3). These findings are robust to different measures of loss aversion and income risk, the inclusion of controls on a large set of socioeconomic characteristics, and different econometric specifications.

We make several contributions to the economic literature. First, we contribute to the literature investigating household saving behavior in general. Our results provide support for the predictions derived from the consumption-saving model by Köszegi and Rabin (2009), and empirically establish that the role of loss aversion on saving is more complex than previously proposed, and in particular, that loss aversion can even foster saving. For example, Thaler and Benartzi's (2004) 'Save More Tomorrow Program' builds on the argument that loss-averse individuals perceive saving a portion of their current income as a loss. However, Thaler and Benartzi (2004) do not measure loss aversion, nor do they account for uncertainty of future income. This is the first paper that investigates empirically the predictions of the model by Köszegi and Rabin (2009).

Our second contribution is to the literature on precautionary savings. The Köszegi and Rabin model (2009) differs from the classical theory (Leland, 1968; Kimball, 1990) by incorporating a behavioral element, namely loss aversion. Traditional theory assumes individuals to conduct a rather complex theoretical optimization of expected utility. The precautionary savings motive resulting from the model by Kôszegi and Rabin (2009) is arguably more intuitive: Individuals save to mitigate (over-weighted) utility losses due to consumption levels below their expectations that might occur if income falls. For this reason, the model might adequately capture saving behavior of populations with low financial education. While the classical theory has been studied extensively in the Western world (e.g., Guiso et al., 1992; Dynan, 1993; Lise, 2013; Bayer et al., 2019; Christelis et al., 2020), ${ }^{3}$ relatively few papers focus on precautionary savings among low-income populations in developing countries (Jalan and Ravallion, 2001; Giles and Yoo, 2007; Paxton and Zhuo, 2011; Michler and Balagtas, 2017). In addition, the existing studies do not consider the role of loss aversion on precautionary saving, i.e., on saving in the presence of income uncertainty. Pagel (2017) builds an expectations-based reference-dependent life-cycle consumption

\footnotetext{
${ }^{3}$ See also the review by Lugilde et al. (2019) on the empirical literature on precautionary savings.
} 
model that depends on this loss aversion-based precautionary savings motive, and empirically shows that it is consistent with a number of puzzling observations, such as a hump-shaped consumption profile over the life-cycle. However, as in most of the studies on precautionary saving, also the empirical approach by Pagel (2017) does not include experimentally elicited preference data. ${ }^{4,5}$ The present study closes the gap with respect to loss aversion and precautionary saving, and thus provides the missing empirical support for theoretical contributions building on this precautionary savings motive and to design future behavioral interventions based on it.

Lastly, we contribute to the broader economic literature empirically relating loss aversion with real-world consequences, including reference-dependent expectations and consumption decisions (e.g., Ericson and Fuster, 2011, or Karle et al., 2015). Benartzi and Thaler (1995) show that loss aversion can explain the equity premium puzzle and affects participation in equity markets. Moreover, there is empirical evidence linking (expectation based) loss aversion and labor markets (e.g., Camerer et al., 1997; Fehr and Goette, 2007; Farber, 2008; Abeler et al., 2011; Imas et al., 2016), sports (Pope and Schweitzer, 2011; Bartling et al., 2015; Allen et al., 2016; Markle et al., 2018), domestic violence (Card and Dahl, 2011), innovation (Rosokha and Younge, 2020), housing markets (Andersen et al., 2019) and student performance (Karle et al., 2020), among others. We contribute to this line of research by focusing on the relation between loss aversion and savings. To our knowledge, we are the first to investigate this relationship empirically with a direct measure of loss aversion at the individual level. Previous work argued that loss aversion is (negatively) related to saving (e.g., Thaler and Benartzi, 2004) or attributed observed behavior to loss aversion (e.g., Fisher and Montalto, 2011) but lacked an appropriate measure of loss aversion at the individual level to measure the relation. The parameter-free elicitation procedure due to Abdellaoui et al. (2007) that we implement in our study provides a state-of-the-art measure of loss aversion on a highly relevant population group.

Our paper may help calibrating models building on the examined precautionary savings motive. Moreover, it might also inform policy design when considering behavioral approaches to increase the savings rate, in particular among those with limited financial education and among

\footnotetext{
${ }^{4}$ A notable exception is Noussair et al. (2014).

${ }^{5}$ Loss aversion in Pagel (2017) is deduced from consumption, income and wealth data using structural estimations at the population level. This approach might yield biased results if individuals self-select into low-income risk occupations based on their risk preferences (Fuchs-Schündeln and Schündeln, 2005).
} 
the poor (for a comprehensive overview of the research on saving among the poor, see Karlan et al., 2014). Based on our findings, we suggest that interventions might focus on the loss associated with failing to save. This could be done, for example, similar to Karlan et al. (2016), who compare the effectiveness of reminders to save that are framed as a loss ("your dreams won't come true") with reminders that are framed as a gain ("your dreams will come true"). They find no significant effects of the frame on a household's saving rate. However, they do not consider income uncertainty. As our research indicates, focusing on unacceptably low levels of consumption or well-being in the future that may result from income uncertainty could help in designing effective interventions to increase savings.

This paper is structured as follows. The next section presents the model of inter-temporal consumption by Köszegi and Rabin (2009) and extends its analysis, from which the hypotheses of the study are derived. Section 3 explains the empirical strategy used to test the predictions of this model, and Section 4 explains how the different measures were obtained. Results are presented in Section 5, and the approaches and findings of the paper are discussed in Section 6. Section 7 concludes.

\section{Theoretical Framework}

The conceptual framework that we use in the analysis is based on the reference-dependent utility model of inter-temporal consumption by Köszegi and Rabin (2009). First, we introduce this model and derive the precautionary motive for saving as presented in their paper. In a second step, we extend the analysis to derive hypotheses relating the strength of the precautionary savings motive with the degree of loss aversion.

The model considers a two-period consumption-saving decision problem where individuals face uncertainty regarding their future wealth. Here, we present the model for the case in which wealth $W$ is a binary random variable and uncertainty is resolved in the second period. In Appendix A.1, we present the two-period model for a more general case where $W$ is non-binary random wealth. 
We assume that with equal probabilities, wealth takes two possible values: $W_{0}+s$ and $W_{0}-s$, where $W_{0}$ is deterministic income and $s>0$ a scalar, reflecting income risk. ${ }^{6}$ An individual has to divide wealth $W$ between consumption $c_{t}$ in two periods, $t=1,2$, maximizing the sum of instantaneous utility in the first period and the expected instantaneous utility in $\mathrm{t}=2$,

$$
U=u_{1}\left(c_{1}\right)+\mathbb{E}\left[u_{2}\left(c_{2}\right)\right]
$$

subject to the budget constraint $c_{1}+c_{2}=W$.

In the first period, there is no uncertainty on income and instantaneous utility is given by

$$
u_{1}\left(c_{1}\right)=m\left(c_{1}\right)
$$

where $m$ is the utility of consumption that is assumed to be three times differentiable, increasing and strictly concave. ${ }^{7}$

The expected instantaneous utility in the second period, $\mathbb{E}\left[u_{2}\left(c_{2}\right)\right]$, depends on the expected utility of consumption in that period, $m$, and on the so-called 'gain-loss utility'. Before the first period starts, it is assumed that agents choose their favorite credible consumption plan, which specifies possibly stochastic consumption levels for each period. This plan is called the Personal Preferred Equilibrium (PPE). ${ }^{8}$ When uncertainty is resolved in the second period and consumption decisions are implemented, plans are updated and lead to new beliefs. Changes in beliefs induce a gain or a loss in utility through 'gain-loss utility' depending on whether new beliefs imply a higher or lower consumption level than previously believed. Following Kahneman and Tversky (1979), it is assumed that individuals weight utility losses different than utility gains by using a factor $\lambda>0$ that captures the degree of loss aversion. For an individual who is loss averse, we have $\lambda>1$, whereas for a gain-seeking individual we have $\lambda<1$.

If income is high (i.e., if $W=W_{0}+s$ ), which occurs with probability $1 / 2$, there is a gain in utility from changes in beliefs, as the individual had planned a lower consumption level $\left(c_{2}^{-}\right)$

\footnotetext{
${ }^{6}$ Results generalize to non-binary random income in the more general model; see the corresponding Proposition 8 in Kôszegi and Rabin (2009), as well as Proposition 1 and its Corollary in this study, for more general results.

${ }^{7}$ We abstract from overconsumption and assume that a deviation in period 1 from the ex-ante optimal plan cannot increase the assessment of the overall utility in period 1; see Proposition 5 in Köszegi and Rabin (2009).

${ }^{8}$ Details on this concept are given in Appendix A.2 or in Köszegi and Rabin (2009).
} 
with probability $1 / 2$. This change is weighted by $\eta>0$, which captures the weight attached to gain-loss utility. Conversely, if income is low, there is a loss in utility since the agent had planned a higher consumption level $\left(c_{2}^{+}\right)$, again with probability $1 / 2$; this change is weighted by $\eta>0$ and $\lambda>0$ to account for loss-averse $(\lambda>1)$ or gain-seeking $(\lambda<1)$ behavior. $^{9}$

Summarizing, the expected instantaneous utility in the second period is given by

$$
\begin{aligned}
\mathbb{E}\left[u_{2}\left(c_{2}\right)\right]= & \frac{1}{2}\left(m\left(c_{2}^{+}\right)+\frac{1}{2} \eta\left(m\left(c_{2}^{+}\right)-m\left(c_{2}^{-}\right)\right)\right) \\
& +\frac{1}{2}\left(m\left(c_{2}^{-}\right)-\frac{1}{2} \lambda \eta\left(m\left(c_{2}^{+}\right)-m\left(c_{2}^{-}\right)\right)\right),
\end{aligned}
$$

where $m$ is the utility of consumption as defined above, $c_{2}^{+}=W_{0}-c_{1}+s$ and $c_{2}^{-}=W_{0}-c_{1}-s$.

As shown by Kôszegi and Rabin (2009), for an interior solution, the optimal consumption path satisfies

$$
m^{\prime}\left(c_{1}\right)=\frac{1}{2} m^{\prime}\left(c_{2}^{+}\right)+\frac{1}{2} m^{\prime}\left(c_{2}^{-}\right)+\frac{1}{4} \eta(\lambda-1)\left[m^{\prime}\left(c_{2}^{-}\right)-m^{\prime}\left(c_{2}^{+}\right)\right] .
$$

To see whether increases in risk, $s$, increase $m^{\prime}\left(c_{1}\right)$, i.e., decrease $c_{1}$ (since $m$ is strictly concave), we apply a Taylor approximation of the right-hand side of (1) around $s=0$ to obtain $^{10}$

$$
m^{\prime}\left(c_{1}\right) \approx m^{\prime}\left(c_{2}\right)+\frac{1}{2} m^{\prime \prime \prime}\left(c_{2}\right) s^{2}+\frac{1}{2} \eta(\lambda-1)\left(-m^{\prime \prime}\left(c_{2}\right)\right) s .
$$

From this derivation, we see that, for a loss-averse individual (i.e., when $\lambda>1$ ), uncertainty causes an increase in savings as consumption decreases in period 1 when $m^{\prime \prime \prime}>0$, but also when the last term dominates the second term in (2). The first condition corresponds to the classical theory of precautionary saving, as initiated by Leland (1968), where a positive third derivative of consumption utility causes the individual to save. Following the assumption of Kôszegi and Rabin (2009) that $m$ is a global utility function, small risks in the model might still be substantial in "practical terms", and thus the last term dominates the second term in (2). ${ }^{11}$

\footnotetext{
${ }^{9}$ The assumption of putting a higher weight on utility below the reference point, hence assuming loss aversion (i.e., $\lambda>1$ ), is common in reference-dependent models. Köszegi and Rabin (2009) call it the "clearly correct assumption", although empirical studies also document 'gain-seeking' behavior (e.g., Schmidt and Traub, 2002). Therefore, we only assume $\lambda>0$ and allow for gain-seeking behavior. See Appendix A.1 for further details.

${ }^{10}$ See Equation (11) in Kőszegi and Rabin (2009).

${ }^{11}$ This assumption is needed, since technically, this is true only for small $s$; see their comment in Footnote 25 in Kôszegi and Rabin (2009).
} 
Generalizing to the case where second-period income has more than just two realizations and where people might overconsume in the first period leads to the first hypothesis from this model. ${ }^{12}$

Hypothesis 1. For loss-averse agents, higher levels of income uncertainty are associated with higher levels of savings.

We now extend the analysis of Köszegi and Rabin (2009) to consider how the degree of loss aversion affects the precautionary savings motive. From both (1) and (2), we see that savings increase in the degree of loss aversion. ${ }^{13}$ This finding can be generalized to non-binary income risk and to overconsuming individuals, i.e., those increasing their consumption relative to the ex-ante optimal level in the first period: Suppose wealth is now equal to $W_{0}+s y$, where $y$ is a non-deterministic mean-zero lottery that is resolved in period 2. Overconsumption is linked to a parameter $\gamma \geq 0$ : If it remains below a certain threshold, individuals overconsume in this more general framework (Appendix A.1). ${ }^{14}$

Proposition 1. For any increasing, strictly concave, three times differentiable consumption utility function $m$, any $\eta>0, \lambda>0, \gamma \geq 0$, and $s$ small and positive, the personal preferred equilibrium consumption rule satisfies $d c_{1} / d \lambda<0$.

The proof of Proposition 1 is in Appendix A.3. From this proposition, we derive the following hypothesis:

Hypothesis 2. When facing income uncertainty, a higher degree of loss aversion is associated with higher savings. This also includes coefficients of loss aversion $\lambda \leq 1$.

Irrespective of Hypotheses 1 and 2 being true (i.e., the degree of loss aversion or uncertainty for loss-averse individuals being positively related to savings), from (1) and (2) we see that the

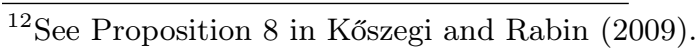

${ }^{13}$ As in the case of uncertainty, it cannot technically be said for sure whether the second-order condition for a utility maximum is satisfied for any amount of risk (as (2) is a Taylor approximation around $s=0)$. However, for small amounts of risk, the condition holds. Yet, following the argument of Kôszegi and Rabin (2009) that small risks in the model can be substantial in practical terms, this restriction comes, just as in their analysis, without major consequences.

${ }^{14}$ Kôszegi and Rabin (2009) show that an individual increases consumption in the first period relative to the ex-ante optimal level if $\gamma<1 / \lambda$; see Appendix A.1 for further details.
} 
effect of loss aversion on savings increases in uncertainty and that the effect of uncertainty on savings increases in loss aversion. As expected, this result generalizes to non-binary income lotteries and holds independently of individuals overconsuming in the first period:

Corollary 1. For any increasing, strictly concave, three times differentiable consumption utility function $m$ and any $\eta>0, \lambda>0, \gamma \geq 0$, the personal preferred equilibrium consumption rule satisfies $d^{2} c_{1} /\left.(d s d \lambda)\right|_{s=0}<0$.

From Corollary 1 and following the interpretation of small risks in the model by Kôszegi and Rabin (2009), we can derive the third hypothesis:

Hypothesis 3. The increase in savings associated with an increase in the degree of loss aversion is an increasing function of income uncertainty. Equivalently, the (positive) relation between income uncertainty and savings is an increasing function of the degree of loss aversion. As in Hypothesis 2, this also includes coefficients of loss aversion $\lambda \leq 1$.

\section{Empirical Strategy}

To test the hypotheses derived from Köszegi and Rabin's (2009) model in Section 2 and to investigate the relationship between income risk, loss aversion on the individual level and savings, we use individual measures of savings, income risk, and loss aversion in our analysis. To test Hypothesis 1 on the positive association between income risk and savings for loss-averse individuals, we run the following regression - with and without restricting our sample to loss-averse individuals: ${ }^{15}$

$$
\text { Savings }_{i}=\beta_{1} s_{i}+\zeta X_{i}+\beta_{0}+\varepsilon_{i}
$$

where Savings ${ }_{i}$ denotes individual accumulated liquid savings of individual $i, s_{i}$ is the individual's income uncertainty, $X_{i}$ is a vector of socioeconomic characteristics for individual $i$, and $\varepsilon_{i}$ is the error term; $\beta_{1}$ and $\zeta$ are regression coefficients estimating the relation between savings and income uncertainty and socioeconomic characteristics, respectively, and $\beta_{0}$ is the intercept of this model. The data would support Hypothesis 1 if $\beta_{1}>0$ (and in a more rigorous sense, if this is the case when restricting the sample to loss-averse individuals).

\footnotetext{
${ }^{15}$ Although agents are generally assumed to be loss averse (e.g., Köszegi and Rabin, 2009), for a rigorous test of Hypothesis 1, the sample has to be restricted to the loss-averse sub-sample.
} 
To test the second hypothesis, postulating that the degree of loss aversion is associated with higher savings when facing income risk, we run the following regression:

$$
\text { Savings }_{i}=\beta_{1} s_{i}+\beta_{2} \lambda_{i}+\zeta X_{i}+\beta_{0}+\varepsilon_{i}
$$

where $\lambda_{i}$ is the degree of loss aversion of individual $i$ with corresponding regression coefficient $\beta_{2}$. Although the population group under study is highly exposed to income uncertainty, we control for the degree of income uncertainty $s_{i}$ for a rigorous test. A positive $\beta_{2}$ would support Hypothesis 2.

Finally, we test Hypothesis 3, claiming that the relation between income uncertainty and savings is an increasing function of the degree of loss aversion, by estimating the following equation:

$$
\text { Savings }_{i}=\beta_{3}\left(s_{i} \times \lambda_{i}\right)+\beta_{1} s_{i}+\beta_{2} \lambda_{i}+\zeta X_{i}+\beta_{0}+\varepsilon_{i}
$$

where $\beta_{3}$ is the regression coefficient of the interaction term of individual loss aversion $\lambda_{i}$ and individual income uncertainty $s_{i}$. Hypothesis 3 is supported if $\beta_{3}>0$. Note that we center income risk measures around mean values and loss aversion around 1, and, to maintain consistency, do so in all models. Hence, $\beta_{1}$ is the main effect of uncertainty for a loss-neutral individual, while $\beta_{2}$ is the main effect of loss aversion estimated at a mean level of income uncertainty. The theoretical model does not provide definitive predictions on savings for loss-neutral individuals facing income risk (in contrast to gain-seeking and loss-averse individuals).

The next section presents the definitions of loss aversion, savings, and income risk, and the data used for these measures.

\section{Data}

The primary data used in the study were collected between October and November 2013 as part of a project investigating the financial vulnerability of low-income households in Bogotá. The study comprised an extensive survey of the financial situation of the households and incentivized economic experiments on risk and time preferences. Secondary data on official unemployment figures were obtained from Colombia's Statistical Department DANE. 
For our primary data collection, we conducted a two-step sampling process. First, low-income neighborhoods were identified by assessing the proportion of people belonging to the two lowest socioeconomic strata. Neighborhoods with a larger proportion of low-income population, and which were assessed as safe for the team to visit, were eligible for the study. Participants for the study were then selected from a list of households in the area in 2010. The criterion for selecting participants was that they should be beneficiaries of the social health insurance, SISBEN. This condition would guarantee that the participants were from low socioeconomic strata.

In total, 640 participants completed the survey and the experiment. The survey lasted around 90 minutes. The experiment was completed at a different location a few days later and took about 20 minutes.

\subsection{Definition of Variables}

Savings We measure savings as the total value of an individual's monetary assets. This includes total savings in checking accounts, certificates of deposit, mutual funds, savings in cash or in other currencies, the value deposited in savings plans (i.e., money to buy a house or to pay for the education of their children), and the net value of loans given. We use the sum of those categories, since in cases of emergency it is possible to withdraw money from all of these savings devices.

Income Risk In the analysis, income risk is measured by i) the official unemployment rate, provided at the locality level (localidad in Spanish) by Colombia's Statistical Department (DANE) and the District Planning Department $(\mathrm{SDP})^{16}$ and ii) the (self-reported and aggregated) risk of becoming unemployed based on survey data. ${ }^{17}$ In order to handle the endogeneity associated with self-reported unemployment risk, we use the average probability at the local planning unit, $U P Z$. This second measure allows for a greater variability through a much finer grid: Typically, a localidad consists of several UPZs; for example, the localidad Suba consists of $12 U P Z s .^{18}$

\footnotetext{
${ }^{16}$ The figures correspond to the 2011 unemployment rate published in 'Índices de Ciudad' by the Secretaría de Planeación, Alcaldía Mayor de Bogotá, and were the most recent numbers at the date of our study.

${ }^{17}$ All individuals who took part in the experiment and who were working at the time of the interview answered the question "What is the probability that you will lose your job next year".

${ }^{18}$ There are 20 localities in Bogotá aggregating more than 110 UPZs; UPZs with fewer than 25 observations were grouped with their neighboring $U P Z(s)$.
} 
We use these measures since unemployment is one of the main sources of income risk with which our population group is confronted, and since health risk, another major source of income risk, is rather difficult to quantify, which would only result in an arguably more noisy and less objective measure. In addition, unemployment is quite high in Colombia. DANE estimated the unemployment rate at 8.64 percent in Bogotá for 2013. The advantage of the measures we use is that they can be considered to be exogenous for a single individual who cannot affect the unemployment rate or aggregated unemployment risk. The assumption that we use is that individuals observe when neighbors lose employment. This makes their subjective individual risk of income loss salient. Objectively, in big cities like Bogotá, where housing is segregated and to a certain degree informal in many areas, it can be assumed that individuals living in the same (poor) neighborhood work on similar job markets and are constrained in relocating for a job, and thus face similar unemployment risks (cf. the spatial mismatch hypothesis going back to Kain (1968), who documented that housing segregation of nonwhite workers in Detroit and Chicago affected their employment outcomes - among them unemployment risk -, and see for example Andersson et al. (2018) for recent empirical support of the now broader question "whether a worker with locally inferior access to jobs is likely to have worse labor market outcomes"). As detailed below, we find support for this conjecture also in our data.

Loss Aversion For the experimental elicitation of loss aversion, we used the non-parametric method for joing elicitation of utility in the loss and the gain domain introduced by Abdellaoui et al. (2007). This method is based on simple lottery choices where individuals compare two lotteries over a series of decision tasks that vary payoffs and probabilities of good and bad states of the world. It is thus equally or less cognitively demanding than other methods (e.g., Holt and Laury, 2005). The method applied corrects for the misperception of probability. Using these choices, it elicits utility points iteratively over a large range of values. The elicited utility points can then be connected to yield a utility function over the gain and loss domain. The advantage of this method is that it is very flexible as it does not require any parametric assumptions over a utility function or probability weighting. Competing methods mostly focus on the elicitation of preferences at just one or a few (arbitrarily) selected points in the interval of interest (e.g., Binswanger, 1980; Eckel and Grossman, 2002; Holt and Laury, 2005). To test whether participants understood the decisions, we included comprehension questions. Participants were able to solve 
them before comparing the lotteries. Moreover, analyzing the data ex-post on the aggregate level, we can reject random decision-making. ${ }^{19}$

The definitions of loss aversion that we apply and the resulting coefficients of loss aversion build on the elicited utility functions. Following Abdellaoui et al. (2007), we use five different definitions of loss aversion, since so far there is no agreement on a definition of loss aversion, and empirically, measures differ considerably (e.g., Bouchouicha et al., 2019; Brown et al., 2021). To be precise, we rely on the definitions by Kahneman and Tversky (1979), Wakker and Tversky (1993), Bowman et al. (1999), Neilson (2002) and Köbberling and Wakker (2005). We also follow Abdellaoui et al. (2007) in the operationalization of resulting measures of loss aversion (summarized in Table 3 below or Table 5 in Abdellaoui et al., 2007), which we explain in detail in Appendix B.1. To incorporate the different definitions of loss aversion, and to ensure that our results are independent of the exact definition of loss aversion, we compute different metameasures of loss aversion. The first meta-measure is the geometric mean of the coefficients resulting from the definitions by Neilson (2002) and Köbberling and Wakker (2005), available for all individuals. ${ }^{20}$ The second meta-measure additionally includes the coefficient based on the definition by Kahneman and Tversky (1979), which we can compute for a subset of 579 participants of the experiment, as this involves derivatives; see Section 5 for details. Finally, we compute a measure relying on all five definitions.

Other Risk Preferences The experimental data were also used to estimate risk preferences corresponding to the curvature of consumption utility $m$ and probability weighting that we use as

\footnotetext{
${ }^{19}$ More specifically, using binomial tests for the whole set of decision tasks as well as for different subsets of the tasks (e.g., decisions involving non-negative outcomes, decisions involving other probabilities than .5), we reject the probability of choosing the left (the right) lottery with a probability of $50 \%$. We can also check single decision items, where we find no evidence for random decision-making neither in decision tasks involving non-negative outcomes nor in those involving non-positive outcomes. For mixed gambles, we cannot reject that the left lottery is chosen in half of the cases (i.e., with a probability of 50\%), which is consistent with our findings with respect to loss aversion (based on a different classification strategy, see below): Aggregating individual data, the sample can neither be classified as loss averse nor gain seeking.

${ }^{20}$ We apply the geometric instead of the arithmetic mean, since all coefficients are ratios, thus centered around 1 , where it is desirable that coefficients of .5 and 2 have a mean of 1 instead of 1.25 . Additionally, the geometric mean is the adequate choice when ranges of single components differ, which is the case for the loss aversion coefficients resulting from the different definitions.
} 
control variables. We use similar procedures as Abdellaoui et al. (2007). In particular, after appropriate rescaling, we estimate the curvature of utility by estimating the parameters of the following power utility function for the gain and loss domains (see Appendix B.2 for details):

$$
m(x)= \begin{cases}-(-x)^{a} & \text { for } a>0,-1 \leq x<0 \\ 0.5 \cdot(x)^{b} & \text { for } b>0,0 \leq x \leq 1\end{cases}
$$

The estimated parameters, referred to as coefficients of risk aversion in expected utility (EU) theory, are used to describe and classify utility curvature. ${ }^{21}$

The experimental method proposed by Abdellaoui et al. (2007) also allows a non-parametric estimation of subjective probabilities. We use this method to estimate the objective probability corresponding to a subjective probability of 50 percent.

Time Preferences To elicit the near future impatience or interest rate, which we also use as control variable, we followed the experimental design by Andersen et al. (2008). Participants were asked whether they would prefer to receive an amount $x$ in 30 days or an amount $x(1+r / 12)$ with $r>0$ in 60 days. This question was asked for different and increasing values of $r$ and participants usually switch from choosing $x$ in 30 days to $x(1+r / 12)$ in 60 days for a sufficiently high $r$. This switching point allows the calculation of a lower and an upper bound of the interest rate. Since choices deal with the concept of receiving money, interpreting the results as impatience is likely more accurate.

In addition, we let participants perform the same task with a more distant time-framing (180 vs. 210 days). This allows us to consider consistency in inter-temporal choice.

Other Control Variables In the empirical analysis, we also control for other covariates that have been found to affect the likelihood of saving or the amount of savings directly or indirectly: Age, gender and the relation to the household head (to capture female-headed households), number of children, family size, whether or not parents are still alive (to capture inheritance), exercising habits and the BMI (to capture health status), education, financial literacy, income situation, homeownership, and financial planning behavior (e.g., Conley and Ryvicker, 2004; Finke et al.,

\footnotetext{
${ }^{21}$ For $x>0$, the utility function is strictly concave if $0<b<1$, linear if $b=1$, and strictly convex if $b>1$. For $x<0$, we have that the function is strictly concave if $a>1$, linear if $a=1$, and strictly convex if $0<a<1$.
} 
2006; Devaney et al., 2007; Sanders and Porterfield, 2010; Fisher and Montalto, 2010, 2011; Van Rooij et al., 2012; Gorbachev and Luengo-Prado, 2019).

\section{Results}

\subsection{Descriptive Statistics}

Summary statistics are reported in Table 2. Participants in the study were between the ages of 24 to 87, with a mean age of 49 years. Our sample consists of roughly 70 percent women. On average, the highest educational attainment was passing the sixth year of school. Financial literacy was also relatively low: The average individual was able to answer roughly only half of the 18 questions concerning, for example, simple math or interest-rate topics correctly. These figures reinforce the need to investigate "behavioral" drivers of saving behavior such as loss aversion: They illustrate that the sample at hand is arguably more likely to be guided by heuristics rather than by a sophisticated optimization process when it comes to saving.

The mean monthly income in an average household was 319,000 COP, which at that time was roughly 170 USD. The poverty line at the date of the interview was approximately 155 USD. Half of the sample was assigned to the lowest socioeconomic strata according to the SISBEN classification. This explains that around 85 percent of the sample does not engage in saving money and that the overall mean of savings is 256,000 COP - approximately 130 USD -, thus less than the average per-capita household income per month. The mean savings of those who were actually saving was around 1,761,000 COP, which corresponds to roughly 900 USD. Those reporting non-zero savings save exclusively in cash (27 percent), in a savings account (20 percent), or exclusively for housing (34 percent). The majority of the sample (74 percent) reported carrying out their financial planning on a day-by-day basis, and more than half of the sample never, or hardly ever, exercises, which is reflected in a mean BMI of 25.7, corresponding to an overweight person.

Summary statistics on income risk are reported in Table 1. The regional unemployment rate ranged from 6.9 percent in the localidad 'Suba' to 11.3 percent in 'San Cristóbal'. 22 The average

\footnotetext{
${ }^{22}$ The figure coming closest to what is commonly referred to as 'unemployment' is the 'Tasa de Desocupados', the rate of unoccupied persons.
} 
Table 1: Summary Statistics of Income Risk Measures

\begin{tabular}{lcccccc}
\hline & Mean & s.d. & Median & Min & Max & Obs. \\
\hline DANE: Unemployment Rate (in pc) & 8.5 & 1.7 & 8.1 & 6.9 & 11.3 & 640 \\
Survey: Unemployment Risk (in pc) & 24.7 & 6.0 & 25.4 & 15.2 & 36.5 & 640 \\
\hline
\end{tabular}

Note: The unemployment rate is measured at the localidad level and relies on secondary data provided by DANE; unemployment risk results from self-reported individual figures in our survey that are averaged at the $U P Z$ level; see Section 4 for details.

Table 2: Summary Statistics

\begin{tabular}{|c|c|c|c|c|c|}
\hline & Mean & s.d. & Min & $\operatorname{Max}$ & Obs. \\
\hline \multicolumn{6}{|l|}{ Individual Information } \\
\hline Age & 49.0 & 13.4 & 24 & 87 & 640 \\
\hline Male $(=1)$ & 0.28 & 0.45 & 0 & 1 & 640 \\
\hline \multicolumn{6}{|l|}{ Relationship to head of $\mathrm{HH}$} \\
\hline Head of household $(=1)$ & 0.64 & 0.48 & 0 & 1 & 640 \\
\hline Partner $(=1)$ & 0.23 & 0.42 & 0 & 1 & 640 \\
\hline Son/Daughter or their partner $(=1)$ & 0.07 & 0.25 & 0 & 1 & 640 \\
\hline Other $(=1)$ & 0.06 & 0.24 & 0 & 1 & 640 \\
\hline \multicolumn{6}{|l|}{ Household Characteristics } \\
\hline Number of adult household members & 2.8 & 1.4 & 1 & 12 & 640 \\
\hline Number of adolescents & 1.2 & 1.3 & 0 & 7 & 640 \\
\hline Father still alive $(=1)$ & 0.31 & 0.46 & 0 & 1 & 640 \\
\hline Mother still alive $(=1)$ & 0.51 & 0.50 & 0 & 1 & 640 \\
\hline \multicolumn{6}{|l|}{ Exercising } \\
\hline Every day $(=1)$ & 0.17 & 0.37 & 0 & 1 & 640 \\
\hline At least once a week $(=1)$ & 0.18 & 0.38 & 0 & 1 & 640 \\
\hline At least once a month $(=1)$ & 0.09 & 0.28 & 0 & 1 & 640 \\
\hline Never or hardly ever $(=1)$ & 0.57 & 0.50 & 0 & 1 & 640 \\
\hline \multicolumn{6}{|l|}{ Other Health Indicators } \\
\hline BMI & 25.7 & 4.3 & 12.9 & 43.0 & 640 \\
\hline \multicolumn{6}{|l|}{ Education } \\
\hline Highest year passed & 5.8 & 3.3 & 0 & 11 & 640 \\
\hline Financial literacy score (max. 18) & 9.3 & 3.4 & 0 & 16 & 640 \\
\hline \multicolumn{6}{|l|}{ Financial Situation of the Household } \\
\hline SISBEN Level $2(=1)$ & 0.50 & 0.50 & 0 & 1 & 640 \\
\hline Size of safety net (\# Persons) & 2.5 & 3.5 & 0 & 60 & 640 \\
\hline Monthly HH income per capita $^{a}$ & 3.19 & 2.26 & 0.01 & 18.00 & 640 \\
\hline Market price of house $^{a}$ & 180.10 & 408.86 & 0.00 & 3000.00 & 640 \\
\hline $\operatorname{Debt}^{a}$ & 17.24 & 65.68 & 0.00 & 588.04 & 640 \\
\hline Savings $^{a}$ & 2.56 & 13.91 & 0.00 & 200.00 & 640 \\
\hline Engaging in saving $(=1)$ & 0.15 & 0.35 & 0 & 1 & 640 \\
\hline Conditional savings & 17.61 & 32.82 & 0.20 & 200.00 & 93 \\
\hline \multicolumn{6}{|l|}{ Planning Horizon } \\
\hline Day to day $(=1)$ & 0.74 & 0.44 & 0 & 1 & 640 \\
\hline Next months $(=1)$ & 0.18 & 0.38 & 0 & 1 & 640 \\
\hline Next year $(=1)$ & 0.05 & 0.21 & 0 & 1 & 640 \\
\hline Next two to five years $(=1)$ & 0.02 & 0.14 & 0 & 1 & 640 \\
\hline Next five to ten years $(=1)$ & 0.01 & 0.11 & 0 & 1 & 640 \\
\hline
\end{tabular}

Note: ${ }^{a}$ Figures reported in 100,000 COP. 
self-reported unemployment risk ranges from 15.2 percent in the UPZ Corabastos (localidad Kennedy) to 36.5 in Comuneros/Alfonso López (localidad Usme). Comparing unaggregated, individual self-reported unemployment risk between these two UPZs shows significant differences, both in the mean and in the distribution, using a two-sided t test $(\mathrm{p}<0.03)$ and an exact Kolmogorov-Smirnov test $(\mathrm{p}<0.1)$, respectively. This suggests that labor markets differ for inhabitants of different neighborhoods, in line with the spatial mismatch hypothesis.

Secondary data on unemployment as provided by DANE reveal an average unemployment rate of $8.5 \%$. This is substantially lower than the mean perceived risk of unemployment based on subjective data (close to $25 \%$ ). This difference can be due the commonly observed overweighting of probabilities below 0.33 , or the fact that more than $50 \%$ of our sample relies on informal employment and is thus, compared to the general population, indeed facing a higher risk of unemployment. The Pearson's correlation coefficient for the two measures of incomre risk is $r=0.505(p<.0001)$, which indicates a positive and large correlation according to Cohen's classification (Cohen, 1992).

The summary statistics for the different measures of loss aversion are presented in Table $3 .^{23}$ Depending on the measure used, we find that on average participants display loss aversion. In our experiment, the lowest mean and median values for the loss aversion coefficients are based on the definitions by Neilson (2002) and Bowman et al. (1999), while the highest coefficients are based on the definition by Köbberling and Wakker (2005). This pattern has also been documented in a recent meta-analysis of empirical estimates of loss aversion (Brown et al., 2021) and by Abdellaoui et al. (2007) (whose protocol we follow; however, they find higher mean and median values for all definitions $)^{24}$. Similar to them we find that some individuals display gain-seeking

${ }^{23}$ For all individuals, we can compute loss aversion coefficients based on the definitions by Neilson (2002) and Köbberling and Wakker (2005). Other definitions are more difficult to operationalize, in particular the ones relying on derivatives. Because some choice tasks involved stochastic dominant options for some individuals, which was a result from the iterative characteristic of the protocol, the number of available utility points differs. We exclude choices resulting from such choice tasks from the analysis, following e.g., Bleichrodt and Pinto (2000), who elicit probability-weighting functions non-parametrically with a comparable protocol. As a result, this hinders the operationalization of the loss aversion coefficients in some cases.

${ }^{24}$ Abdellaoui et al. (2007) report that loss aversion coefficients based on the definitions by Bowman et al. (1999) and Neilson (2002) have the lowest mean (0.74 and 1.07) and median values (0.74 and 0.43) in their study, where the latter is below 1 for both definitions. The highest value for the mean and median they obtain for loss aversion, as defined by Köbberling and Wakker (2005), with a mean of 8.27 and a standard deviation of 
behavior.

In general, the measures of loss aversion display a large and significant degree of positive correlation with each other (summarized in Table 5 in Appendix D). The only measure that has a low degree of correlation with all other measures is the Bowman measure that is positively and significantly correlated only with the Neilson measure.

\subsection{Empirical Results}

To test our hypotheses, we run three different models, as explained with detail in Section 3. As the outcome variable - savings - is skewed, non-negative and contains a large number of zeros resulting from not engaging in saving, we apply a Negative Binomial Hurdle model. This model is a two-part model, where the probability of engaging in saving and the amount of savings is estimated separately and by different models. Using a logit-model, the probability of 'passing the hurdle' and actually engaging in saving is estimated. The (strictly positive) amount of savings once the hurdle is passed is estimated using a Truncated Negative Binomial model. In Appendix C.1, we explain the model and its choice in more detail, and give the formula for computation of marginal effects on the outcome. In Appendix C.2, we discuss possible alternative models.

Table 4 presents the estimated coefficients. The columns labeled 'DANE' present the results for the measure of income risk based on the unemployment rate (secondary data obtained from DANE), while the columns labeled 'Survey' present the results for the measure that uses the unemployment risk based on survey data (see Section 4). We present the results separately by the likelihood to save (upper panel) and the amount of savings, given that an individual is actually saving (i.e., conditional saving, lower panel).

Estimation results of a direct test of Hypothesis 1 are presented below 'Model 1' and 'Model 1b' in Table 4. The first two columns present the results for the entire sample, while the columns labeled 'Model 1b' present the results for the sub-population of loss-averse individuals in the sample. All models control for main socioeconomic variables affecting savings, as well as for region and occupation (see the list in Table 2). ${ }^{25}$ These results partly support Hypothesis 1.

15. Other studies focusing on monetary or health outcomes have found individual mean values between 0.11 and 19.861 (Brown et al., 2021) relying on different definitions of loss aversion.

${ }^{25}$ In Model 1b, however, we can only control for a subset of these variables due to the low number of observations. 
Table 3: Summary Statistics of Experimental Measures

\begin{tabular}{|c|c|c|c|c|c|}
\hline & Mean & s.d. & Median & IQR & Obs. \\
\hline \multicolumn{6}{|l|}{ Single Measures of Loss Aversion } \\
\hline $\begin{array}{l}\text { Kahneman-Tversky (KT) } \\
-\mu(-x) / \mu(x)\end{array}$ & 1.1 & 2.7 & 0.4 & $0.1,1.1$ & 579 \\
\hline $\begin{array}{l}\text { Neilson (N) } \\
\qquad(\mu(-x) /-x) /(\mu(y) / y)\end{array}$ & 0.2 & 0.5 & 0.0 & $0.0,0.1$ & 640 \\
\hline $\begin{array}{c}\text { Wakker-Tversky (WT) } \\
\mu^{\prime}(-x) / \mu^{\prime}(x)\end{array}$ & 12.3 & 110.9 & 0.1 & $0.0,0.3$ & 564 \\
\hline $\begin{array}{l}\text { Bowman (B) } \\
\quad \inf \mu^{\prime}(-x) / \sup \mu^{\prime}(x)\end{array}$ & 0.1 & 0.2 & 0.0 & $0.0,0.0$ & 564 \\
\hline $\begin{array}{l}\text { Köbberling-Wakker (KW) } \\
\qquad \mu^{\prime}\left(0_{-}\right) / \mu^{\prime}\left(0_{+}\right)\end{array}$ & 10.9 & 76.6 & 0.2 & $0.0,1.0$ & 640 \\
\hline \multicolumn{6}{|l|}{ Meta Measures of Loss Aversion } \\
\hline Meta Measure $1(\mathrm{KW}, \mathrm{N})$ & 1.1 & 4.6 & 0.1 & $0.0,0.4$ & 640 \\
\hline Meta Measure $2(\mathrm{KT}, \mathrm{KW}, \mathrm{N})$ & 1.0 & 3.1 & 0.1 & $0.0,0.6$ & 579 \\
\hline Meta Measure 3 (all) & 0.3 & 1.0 & 0.1 & $0.0,0.2$ & 509 \\
\hline \multicolumn{6}{|l|}{ Impatience } \\
\hline Near future impatience & 29.6 & 15.2 & 22.0 & $16.0,50.0$ & 640 \\
\hline Increase in patience over time & 0.3 & 16.3 & 0.9 & $-2.9,0.9$ & 640 \\
\hline \multicolumn{6}{|l|}{ Risk Preferences } \\
\hline Utility Curvature: Gain Domain & 6.0 & 29.9 & 0.7 & $0.2,2.5$ & 640 \\
\hline Utility Curvature: Loss Domain & 8.0 & 16.0 & 1.1 & $0.5,3.5$ & 640 \\
\hline Probability Weighting: Gain Domain & 41.5 & 32.9 & 40.6 & $9.4,71.9$ & 640 \\
\hline Probability Weighting: Loss Domain & 68.5 & 28.5 & 78.1 & $46.9,96.9$ & 640 \\
\hline
\end{tabular}

Note: The measures and meta-measures of loss aversion are described in Section 4 and in Appendix B.1 with greater detail. Near future impatience is the mean annual interest rate, see Section 4. Utility curvature is the parameter of a power utility function and probability weighting is the probability that is perceived as $50 \%$; see Section 4 . 
Consistently with the predictions, we find that income risk is positively and significantly related with the amount of savings, given that an individual is actually saving. This result holds both for the complete sample and for the sub-population of loss-averse individuals. Yet, contrary to the predictions, the likelihood to save is negatively related with income risk for the loss-averse population in one of the two estimated models. Thus, we come back to Hypothesis 1 with a more detailed analysis below.

Estimation results of a direct test of Hypothesis 2 are reported in 'Model 2' of Table 4. From the results, we deduce that an increase in loss aversion is associated with an increase in both the likelihood to save and the amount of conditional savings. This result is independent of controlling for income risk, and it is robust to using alternative measures of loss aversion. ${ }^{26} \mathrm{We}$ summarize our findings with respect to Hypothesis 2:

Result 1. An increasing degree of loss aversion is associated with an increase in savings - at the extensive and the intensive margin.

Model 3 allows us to test Hypothesis 3, but we may also use these insights to evaluate Hypothesis 1 and gain a deeper understanding of Result 1 - in addition to the results from the direct tests (Model 1, Model 1b, and Model 2). We find that the likelihood to save is not correlated with income risk. Yet, supporting the theoretical model and in line with the results from Model 1 and Model 1b, we find that conditional savings are positively associated with income risk, and statistically significant when using the survey measure for unemployment risk. As the coefficient of loss aversion is centered around one, the coefficient of income risk shows the relation between income risk and the likelihood to save or savings for a loss-neutral agent. As the interaction term of loss aversion and income risk is positive and significant, we find support for Hypothesis 1:

Result 2. An increase in income risk is associated with an increase in savings, in particular for loss-averse individuals (as specified in Hypothesis 1).

The two just mentioned positive and significant coefficients of the interaction terms between loss aversion and income risk indicate that the increase in savings due to income risk is increasing with the degree of loss aversion. Hence, this result supports Hypothesis 3.

\footnotetext{
${ }^{26}$ Estimation results for different measures of loss aversion are presented in Tables 6 and 7 in the Appendix.
} 


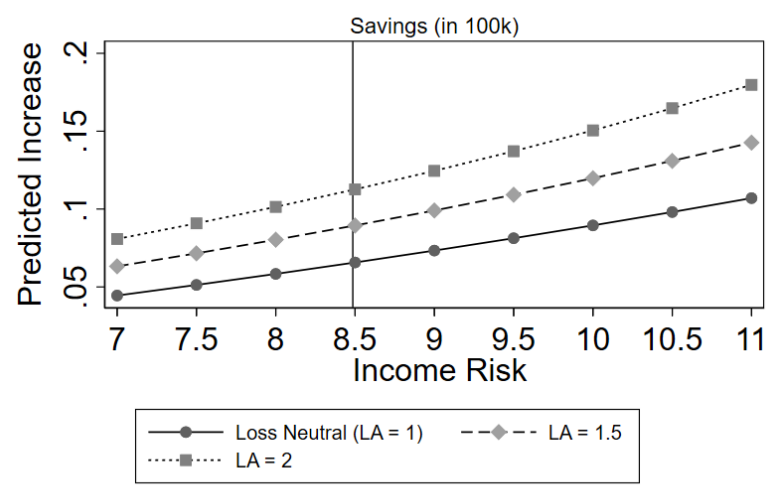

(a) Income Risk: Unemployment Rate (DANE)

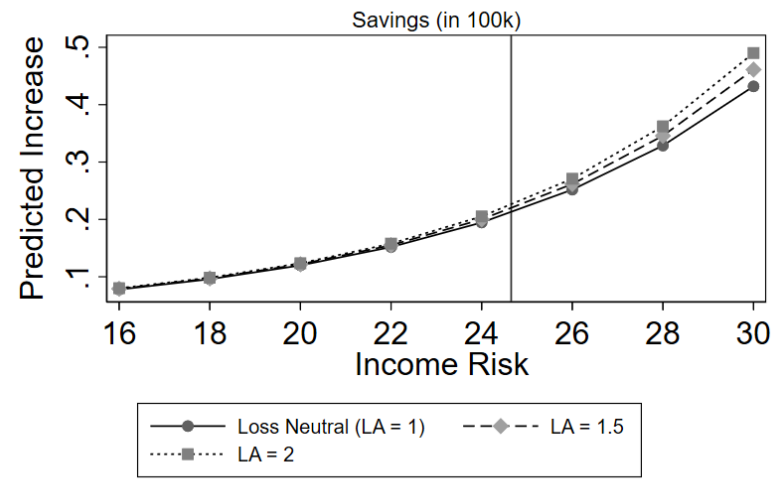

(b) Income Risk: Unemployment Risk (Survey)

Figure 1: Marginal Effect of Income Risk on Predicted Savings as Function of Loss Aversion

Note: Marginal effects (according to Equation (4) in Appendix C.1) using mean values for remaining covariates and estimates from fitting Model 3; see Table 4 for the corresponding coefficients and Figure 4 for marginal effects on the intensive and extensive margins. Vertical lines indicate the mean values of the corresponding measure of income risk. Income risk is expressed in percent and the predicted increase in savings in 100,000 COP.

Result 3. The relationship between income risk and savings is an increasing function of the degree of loss aversion. Equivalently, the relationship between loss aversion and savings is an increasing function of the degree of income risk.

Finally, loss aversion is positively related with the likelihood to save (DANE measure), which is consistent with the theoretical model. However, it is negatively related with conditional savings (Survey measure). As income risk measures are centered around their mean values, this finding, and the results from Model 2, suggest that Result 1 is driven by individuals facing a somewhat elevated income risk.

To assess magnitudes of the overall relations of income risk and loss aversion, we compute the marginal effects (at mean values) on the predicted amount of (unconditional) savings, resulting from estimating Model 3.

Figure 1 displays the corresponding marginal effects of income risk on predicted total savings for gain-seeking to loss-neutral behavior $(\lambda=1)$, moderate loss aversion $(\lambda=1.5)$ and high loss aversion $(\lambda=2){ }^{27}$ We find that an increase in income risk is always associated with an increase in total savings - independent of the degree of loss aversion and the level of income risk. Furthermore, we find that the increase associated with an increase in income risk is larger, the

\footnotetext{
${ }^{27}$ The marginal effects on the intensive and extensive margin are printed in Appendix D; see Figure 4.
} 
Table 4: Results from Estimating Model 1, Model 2, and Model 3 Using a Negative Binomial Hurdle Model and Different Measures of Income Risk

\begin{tabular}{|c|c|c|c|c|c|c|c|c|}
\hline & \multicolumn{2}{|c|}{ Model 1} & \multicolumn{2}{|c|}{ Model 1b } & \multicolumn{2}{|c|}{ Model 2} & \multicolumn{2}{|c|}{ Model 3} \\
\hline & DANE & Survey & DANE & Survey & DANE & Survey & DANE & Survey \\
\hline \multicolumn{9}{|l|}{ Likelihood of Saving } \\
\hline \multirow[t]{2}{*}{ Income Risk } & -0.069 & 0.026 & $-0.395^{\star}$ & -0.001 & -0.068 & 0.027 & -0.070 & 0.025 \\
\hline & $(0.68)$ & $(-0.68)$ & $(1.93)$ & $(0.01)$ & $(0.66)$ & $(-0.71)$ & $(0.68)$ & $(-0.66)$ \\
\hline \multirow[t]{2}{*}{ Loss Aversion } & & & & & $0.041^{\star}$ & $0.042^{\star}$ & $0.039^{\star}$ & 0.032 \\
\hline & & & & & $(-1.68)$ & $(-1.74)$ & $(-1.88)$ & $(-1.15)$ \\
\hline Loss Aversion & & & & & & & 0.008 & 0.012 \\
\hline × Income Risk & & & & & & & $(-0.83)$ & $(-1.55)$ \\
\hline \multicolumn{9}{|l|}{ Amount of Savings } \\
\hline \multirow[t]{2}{*}{ Income Risk } & 0.140 & $0.139^{\star \star \star}$ & $0.883^{\star \star \star}$ & $0.130^{\star \star \star}$ & 0.199 & $0.145^{\star \star \star}$ & 0.211 & $0.150^{\star \star \star}$ \\
\hline & $(0.94)$ & $(2.63)$ & $(3.37)$ & $(6.02)$ & $(1.36)$ & $(2.90)$ & $(1.56)$ & $(3.35)$ \\
\hline \multirow[t]{2}{*}{ Loss Aversion } & & & & & $0.058^{\star \star}$ & $0.062^{\star \star \star}$ & -0.032 & $-0.177^{\star \star \star}$ \\
\hline & & & & & $(2.55)$ & $(2.61)$ & $(-0.82)$ & $(-3.25)$ \\
\hline Loss Aversion & & & & & & & $0.044^{\star \star \star}$ & $0.022^{\star \star \star}$ \\
\hline$\times$ Income Risk & & & & & & & $(2.89)$ & $(4.47)$ \\
\hline Controls & 25 & 25 & 6 & 6 & 25 & 25 & 25 & 25 \\
\hline Region & Yes & Yes & No & No & Yes & Yes & Yes & Yes \\
\hline Occupation & Yes & Yes & No & No & Yes & Yes & Yes & Yes \\
\hline Observations & 640 & 640 & 97 & 97 & 640 & 640 & 640 & 640 \\
\hline
\end{tabular}

${ }^{\star} \mathrm{p}<0.1,{ }^{\star \star} \mathrm{p}<0.05,{ }^{\star \star \star} \mathrm{p}<0.01$. t-values in parentheses.

Note: The dependent variable is the sum of all self-reported savings data in various saving devices, see Section 4 . In this Negative Binomial Hurdle model, the participation equation estimates the likelihood to engage in saving, while the second equation estimates conditional savings - the amount of savings, given that a person is saving any money. The coefficient of loss aversion is centered at one and measured by a continuous and experimentally elicited meta-measure, based on the definitions of loss aversion by Neilson (2002) and Köbberling and Wakker (2005), see Appendix B.1. Income risk is centered at the mean and is based on different measures, one of them relying on secondary data (DANE measure); see Section 4 for details. We control for variables listed in Tables 2 and 3. Furthermore, we control for regional and occupational sector at the localidad level and for the working sectors according to the ISIC classification of economic activities, if indicated. We account for potential heteroskedasticity by using robust standard errors. 
higher the income risk and the higher the degree of loss aversion are. This result holds for both measures of income risk, and is consistent with Hypothesis 3.

In terms of the magnitude of the relation, the result depends on the source of data. The estimations for the secondary data (DANE) imply that, when the average regional unemployment rate rises from 8.5 to 9.5 percent, for a moderately loss-averse sample, there is an increase in the average total savings of about 10,000 COP, or roughly 5 USD. This corresponds to a relatively small increase in savings of 4 percent, which is due to the small proportion of individuals engaging in saving. However, when the model is estimated using survey data on unemployment risk, the effect on the predicted relation of income risk and savings is nearly twice as large.

We now turn to the predicted magnitude of an increase in loss aversion on savings, again controlling for the degree of income risk and including the interaction term between loss aversion and income risk (see column 'Model 3'). Figure 2 presents the estimated total marginal effects of an increase in loss aversion for different income risk levels (average level of income risk, high level of income risk, defined as the third quartile of the distribution of income risk, very high, and an extremely high income risk, corresponding to the $90 \%$ and $95 \%$ quantile of the income risk distribution). The marginal plot relying on the secondary DANE data (Figure 2(a)) indicates a positive effect of a one-unit increase in loss aversion on predicted savings already for average levels of income risk. Using survey data (Figure 2(b)), we find that only when facing a very high income risk, a one-unit increase in loss aversion is predicted to increase savings. These results clarify the dominant role on total savings of the coefficients in the savings equation in Table 4, where coefficients of loss aversion correspond to an average level of income risk (income risk measures are centered around the mean). In particular, for average levels of income risk, we cannot unambiguously expect more loss averse individuals to save more, as only at very high levels of income risk, predictions relying on both measures of income risk result in an increase in savings.

\subsection{Robustness Tests}

In the literature, various definitions of loss aversion have been proposed, but none can be considered standard (Abdellaoui et al., 2007). To address this issue, we have constructed different meta-measures of loss aversion combining two or more definitions. Our results are robust to 


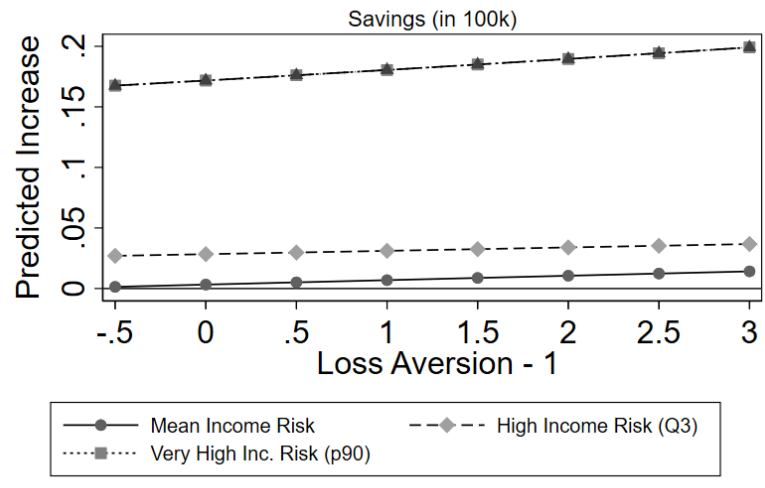

(a) Income Risk: Unemployment Rate (DANE)

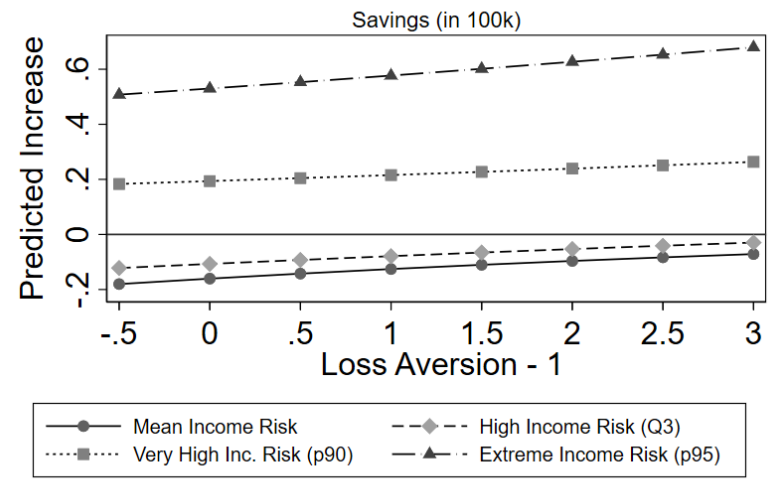

(b) Income Risk: Unemployment Risk (Survey)

Figure 2: Marginal Effect of Loss Aversion on Predicted Savings as Function of Income Risk

Note: Marginal effects (according to Equation (4) in Appendix C.1) using mean values for remaining covariates and estimates from fitting Model 3; see Table 4 for the corresponding coefficients and Figure 5 for marginal effects on the intensive and extensive margins. The predicted increase in savings is expressed in 100,000 COP.

using any of the different meta-measures of loss aversion for both Model 2, and Model 3. We report results of these robustness tests in Tables 6 to 8 in Appendix D.

\section{Discussion}

Our findings confirm the different hypotheses on the positive associations between savings, loss aversion, and income uncertainty derived from the model by Köszegi and Rabin (2009).

We find that our sample is relatively less loss averse than the one in Abdellaoui et al. (2007) - a sample from Europe. Yet, other studies also find considerably lower shares of loss aversion at the individual level (e.g., Schmidt and Traub, 2002; Bleichrodt and Pinto, 2002). Besides, the metaanalysis by Brown et al. (2021) suggests that people from Latin America are less loss averse than, e.g., those from North America or Europe. Had, however, our implementation of the method resulted in an equal underestimation of the degree of loss aversion for every individual, and we should thus assume higher coefficients for every individual, this would -- depending on the assumed shift — result in significant estimations for both income risk coefficients. Qualitatively, it leaves our results unaffected. ${ }^{28}$

\footnotetext{
${ }^{28}$ These results can be obtained from the authors.
} 
With respect to saving, it is sometimes argued that the poor are too poor to save. In our sample, the mean household per-capita income lies near the poverty level, and employment is mostly informal. Our findings, however, build on variation within the sample, and establish that despite possible budget constraints, income uncertainty and loss aversion induce savings. We believe that these findings are important exactly because our sample might face budget constraints, as it illustrates how even those who have very little to save could be triggered to increase their saving, for example by illustrating the possible consequences of uncovered income shocks, and highlighting the associated "loss" in consumption. Nevertheless, it would be of great interest to validate this study's findings with other data from other samples which have other sociodemographic characteristics.

In a similar vein, investigating the predictions resulting from the model by Köszegi and Rabin (2009) with alternative measures of income risk would be of great interest. For example, using administrative income or health data could be valuable, although relatively challenging from an implementation point of view, especially in settings without strong social security systems in place.

\section{Conclusion}

In this paper, we have tested whether the theoretical predictions of the inter-temporal model of consumption and saving by Köszegi and Rabin (2009) can be empirically supported. More specifically, we have tested whether loss-averse individuals who face income risk hold higher savings, which would be consistent with a precautionary savings motive based on loss aversion (Hypothesis 1). Our results support this hypothesis. A one-percent increase in income risk is associated with an increase of 4 to 8 percent of total savings. Secondly, we have tested whether individuals who exhibit a higher degree of loss aversion hold more savings than individuals with a lower degree of loss aversion, given that they face income risk (Hypothesis 2). Our results support this hypothesis, on average, and a detailed analysis shows that this is driven by individuals facing a high level of income risk. Lastly, we have investigated whether the increase in savings associated with an increase in income risk is larger, the higher the degree of loss aversion is (Hypothesis 3). Also for this last hypothesis, we find very strong support. 
Our findings can be used to calibrate models, but also to inform policy-makers: Savings and pension campaigns could stress the uncertainty of future income to boost savings. Moreover, if future income is uncertain, a higher degree of loss aversion can be expected to induce an additional savings motive compared to a lower degree of loss aversion, so people should be reminded that it is unlikely that they will be able to maintain their current standard of living when their income drops. Although we admit that raising saving rate remains a challenge in developing countries, several studies have demonstrated that this is possible (e.g., Ashraf et al., 2006; Dupas and Robinson, 2013; Karlan et al., 2014), and also the heterogeneity we observe in our data supports this claim. Moreover, we like to stress that the relevance of our results is in no way limited to developing nations: Social security systems are far from perfect in numerous countries in the Western world, too, as our examples in the introduction illustrate. In these settings, our insights on a saving model that accounts for behavioral aspects should be equally helpful. 


\section{References}

Abdellaoui, M., H. Bleichrodt, and C. Paraschiv (2007). Loss aversion under prospect theory: A parameter-free measurement. Management Science 53(10), 1659-1674.

Abeler, J., A. Falk, L. Goette, and D. Huffman (2011). Reference points and effort provision. American Economic Review 101(2), 470-492.

Allen, E. J., P. M. Dechow, D. G. Pope, and G. Wu (2016). Reference-dependent preferences: Evidence from marathon runners. Management Science 63(6), 1657-1672.

Andersen, S., C. Badarinza, L. Liu, J. Marx, and T. Ramadorai (2019). Reference dependence in the housingmarket. Discussion Paper 14147, Centre for Economic Policy Research.

Andersen, S., G. W. Harrison, M. I. Lau, and E. E. Rutström (2008). Eliciting risk and time preferences. Econometrica 76(3), 583-618.

Andersson, F., J. C. Haltiwanger, M. J. Kutzbach, H. O. Pollakowski, and D. H. Weinberg (2018). Job displacement and the duration of joblessness: The role of spatial mismatch. The Review of Economics and Statistics 100(2), 203-218.

Ashraf, N., D. Karlan, and W. Yin (2006). Tying Odysseus to the mast: Evidence from a commitment savings product in the Philippines. The Quarterly Journal of Economics 121(2), $635-672$.

Barberis, N. C. (2013). Thirty years of prospect theory in economics: A review and assessment. Journal of Economic Perspectives 27(1), 173-196.

Bartling, B., L. Brandes, and D. Schunk (2015). Expectations as reference points: Field evidence from professional soccer. Management Science 61(11), 2646-2661.

Bayer, C., R. Lütticke, L. Pham-Dao, and V. Tjaden (2019). Precautionary savings, illiquid assets, and the aggregate consequences of shocks to household income risk. Econometrica 87(1), $255-290$.

Benartzi, S. and R. H. Thaler (1995). Myopic loss aversion and the equity premium puzzle. The Quarterly Journal of Economics 110(1), 73-92. 
Binswanger, H. P. (1980). Attitudes toward risk: Experimental measurement in rural India. American Journal of Agricultural Economics 62(3), 395-407.

Bleichrodt, H. and J. L. Pinto (2000). A parameter-free elicitation of the probability weighting function in medical decision analysis. Management Science 46(11), 1485-1496.

Bleichrodt, H. and J. L. Pinto (2002). Loss aversion and scale compatibility in two-attribute trade-offs. Journal of Mathematical Psychology 46(3), 315-337.

Bouchouicha, R., L. Deer, A. G. Eid, P. McGee, D. Schoch, H. Stojic, J. Ygosse-Battisti, and F. M. Vieider (2019). Gender effects for loss aversion: Yes, no, maybe? Journal of Risk and Uncertainty 59(2), 171-184.

Bowman, D., D. Minehart, and M. Rabin (1999). Loss aversion in a consumption-savings model. Journal of Economic Behavior 83 Organization 38(2), 155-178.

Brown, A. L., T. Imai, F. Vieider, and C. Camerer (2021). Meta-analysis of empirical estimates of loss-aversion. Working Paper 8848, CESifo.

Camerer, C., L. Babcock, G. Loewenstein, and R. Thaler (1997). Labor supply of New York City cabdrivers: One day at a time. The Quarterly Journal of Economics 112(2), 407-441.

Card, D. and G. B. Dahl (2011). Family violence and football: The effect of unexpected emotional cues on violent behavior. The Quarterly Journal of Economics 126(1), 103-143.

Cardenas, J. C. and J. Carpenter (2013). Risk attitudes and economic well-being in Latin America. Journal of Development Economics 103, 52-61.

Christelis, D., D. Georgarakos, T. Jappelli, and M. van Rooij (2020). Consumption uncertainty and precautionary saving. The Review of Economics and Statistics 102(1), 148-161.

Christian, C., L. Hensel, and C. Roth (2019). Income shocks and suicides: Causal evidence from Indonesia. The Review of Economics and Statistics 101(5), 905-920.

Clark, A. E., C. D'Ambrosio, and S. Ghislandi (2016). Adaptation to poverty in long-run panel data. The Review of Economics and Statistics 98(3), 591-600.

Cohen, J. (1992). Statistical power analysis. Current Directions in Psychological Science 1(3), $98-101$. 
Conley, D. and M. Ryvicker (2004). The price of female headship: Gender, inheritance, and wealth accumulation in the United States. Journal of Income Distribution 13(3/4), 41-56.

Dercon, S. (2010). Risk, poverty, and human development: What do we know, what do we need to know? In R. Fuentes-Nieva and P. A. Seck (Eds.), Risk, Shocks, and Human Development: On the Brink, pp. 15-39. London, UK: Palgrave Macmillan.

Devaney, S. A., S. T. Anong, and S. E. Whirl (2007). Household savings motives. Journal of Consumer Affairs 41(1), 174-186.

D'Exelle, B. and A. Verschoor (2015). Investment behaviour, risk sharing and social distance. The Economic Journal 125(584), 777-802.

Dupas, P. and J. Robinson (2013). Why don't the poor save more? Evidence from health savings experiments. American Economic Review 103(4), 1138-1171.

Dynan, K. E. (1993). How prudent are consumers? Journal of Political Economy 101(6), $1104-1113$.

Eckel, C. C. and P. J. Grossman (2002). Sex differences and statistical stereotyping in attitudes toward financial risk. Evolution and Human Behavior 23(4), 281-295.

Ericson, K. M. M. and A. Fuster (2011). Expectations as endowments: Evidence on referencedependent preferences from exchange and valuation experiments. The Quarterly Journal of Economics 126(4), 1879-1907.

Farber, H. S. (2008). Reference-dependent preferences and labor supply: The case of New York City taxi drivers. American Economic Review 98(3), 1069-1082.

Federal Reserve Board (2020). Report on the economic well-being of U.S. households in 2019. https://www.federalreserve.gov/publications/ 2020-economic-well-being-of-us-households-in-2019-preface.htm. Last accessed on 3 March 2021.

Fehr, E. and L. Goette (2007). Do workers work more if wages are high? Evidence from a randomized field experiment. American Economic Review 97(1), 298-317.

Finke, M. S., S. J. Huston, and D. L. Sharpe (2006). Balance sheets of early boomers: Are they different from pre-boomers? Journal of Family and Economic Issues 27(3), 542-561. 
Fisher, P. J. and C. P. Montalto (2010). Effect of saving motives and horizon on saving behaviors. Journal of Economic Psychology 31(1), 92-105.

Fisher, P. J. and C. P. Montalto (2011). Loss aversion and saving behavior: Evidence from the 2007 U.S. Survey of Consumer Finances. Journal of Family and Economic Issues 32(1), 4-14.

Fuchs-Schündeln, N. and M. Schündeln (2005). Precautionary savings and self-selection: Evidence from the German reunification "experiment". The Quarterly Journal of Economics 120(3), 1085-1120.

Giles, J. and K. Yoo (2007). Precautionary behavior, migrant networks, and household consumption decisions: An empirical analysis using household panel data from rural China. The Review of Economics and Statistics 89(3), 534-551.

Gorbachev, O. and M. J. Luengo-Prado (2019). The credit card debt puzzle: The role of preferences, credit access risk, and financial literacy. The Review of Economics and Statistics 101 (2), 294-309.

Grogger, J. T. and R. T. Carson (1991). Models for truncated counts. Journal of Applied Econometrics 6(3), 225-238.

Guiso, L., T. Jappelli, and D. Terlizzese (1992). Earnings uncertainty and precautionary saving. Journal of Monetary Economics 30(2), 307-337.

Holt, C. A. and S. K. Laury (2005). Risk aversion and incentive effects: New data without order effects. American Economic Review 95(3), 902-904.

Imas, A., S. Sadoff, and A. Samek (2016). Do people anticipate loss aversion? Management Science 63(5), 1271-1284.

Jalan, J. and M. Ravallion (2001). Behavioral responses to risk in rural China. Journal of Development Economics 66(1), 23-49.

Kahneman, D. and A. Tversky (1979). Prospect theory: An analysis of decision under risk. Econometrica 47(2), 263-292.

Kain, J. F. (1968). Housing segregation, negro employment, and metropolitan decentralization. The Quarterly Journal of Economics 82(2), 175-197. 
Karlan, D., M. McConnell, S. Mullainathan, and J. Zinman (2016). Getting to the top of mind: How reminders increase saving. Management Science 62(12), 3393-3411.

Karlan, D., A. L. Ratan, and J. Zinman (2014). Savings by and for the poor: A research review and agenda. Review of Income and Wealth 60(1), 36-78.

Karle, H., D. Engelmann, and M. Peitz (2020). Student performance and loss aversion. Discussion Paper 150, Rheinische Friedrich-Wilhelms-Universität Bonn und Universität Mannheim - Collaborative Research Center Transregio 224, Bonn und Mannheim.

Karle, H., G. Kirchsteiger, and M. Peitz (2015). Loss aversion and consumption choice: Theory and experimental evidence. American Economic Journal: Microeconomics 7(2), 101-20.

Kőszegi, B. and M. Rabin (2009). Reference-dependent consumption plans. American Economic Review 99(3), 909-936.

Kimball, M. S. (1990). Precautionary saving in the small and in the large. Econometrica 58(1), $53-73$.

Köbberling, V. and P. P. Wakker (2005). An index of loss aversion. Journal of Economic Theory 122(1), 119-131.

Leland, H. E. (1968). Saving and uncertainty: The precautionary demand for saving. The Quarterly Journal of Economics 82(3), 465-473.

Lise, J. (2013). On-the-job search and precautionary savings. The Review of Economic Studies $80(3), 1086-1113$.

Loayza, N., L. Servén, and N. Sugawara (2009). Informality in Latin America and the Caribbean. Working Paper 4888, World Bank Policy Research.

Lugilde, A., R. Bande, and D. Riveiro (2019). Precautionary saving: A review of the empirical literature. Journal of Economic Surveys 33(2), 481-515.

Markle, A., G. Wu, R. White, and A. Sackett (2018). Goals as reference points in marathon running: A novel test of reference dependence. Journal of Risk and Uncertainty 56(1), 19-50.

Michler, J. D. and J. V. Balagtas (2017). The importance of the savings device in precautionary savings: Empirical evidence from rural Bangladesh. Agricultural Economics 48(2), 129-141. 
Neilson, W. S. (2002). Comparative risk sensitivity with reference-dependent preferences. Journal of Risk and Uncertainty 24(2), 131-142.

Noussair, C. N., S. T. Trautmann, and G. v. d. Kuilen (2014). Higher order risk attitudes, demographics, and financial decisions. The Review of Economic Studies 81(1), 325-355.

Odean, T. (1998). Are investors reluctant to realize their losses? The Journal of Finance 53(5), $1775-1798$.

Pagel, M. (2017). Expectations-based reference-dependent life-cycle consumption. The Review of Economic Studies 84(2), 885-934.

Paxton, J. and F. Zhuo (2011). Economic shocks and savings behavior by the rural poor. Economics Bulletin 31(4), 3286-3293.

Pope, D. G. and M. E. Schweitzer (2011). Is Tiger Woods loss averse? Persistent bias in the face of experience, competition, and high stakes. American Economic Review 101(1), 129-57.

Rosokha, Y. and K. Younge (2020). Motivating innovation: The effect of loss aversion on the willingness to persist. The Review of Economics and Statistics 102(3), 569-582.

Sanders, C. K. and S. L. Porterfield (2010). The ownership society and women: Exploring female householders' ability to accumulate assets. Journal of Family and Economic Issues 31(1), 90106.

Schmidt, U. and S. Traub (2002). An experimental test of loss aversion. Journal of Risk and Uncertainty 25(3), 233-249.

Secretaría de Planeación, Alcaldía Mayor de Bogotá (2014). Índices de ciudad. http:// bibliotecadigital.ccb.org.co/handle/11520/8554. Last accessed on 3 March 2021.

Stampini, M., M. Robles, M. Sáenz, P. Ibarrarán, and N. Medellín (2016). Poverty, vulnerability, and the middle class in Latin America. Latin American Economic Review 25(4), 1-44.

Thaler, R. H. and S. Benartzi (2004). Save more tomorrow ${ }^{T M}$ : Using behavioral economics to increase employee saving. Journal of Political Economy 112(S1), S164-S187.

Tovar, J. and M. Urrutia (2017). The impact of social safety net programs on household savings in Colombia. The Developing Economies 55(1), 23-37. 
Van Rooij, M. C., A. Lusardi, and R. J. Alessie (2012). Financial literacy, retirement planning and household wealth. The Economic Journal 122(560), 449-478.

Wakker, P. (2008). Explaining the characteristics of the power (CRRA) utility family. Health Economics 17(12), 1329-1344.

Wakker, P. and A. Tversky (1993). An axiomatization of cumulative prospect theory. Journal of Risk and Uncertainty 7(2), 147-175.

Wooldridge, J. M. (2013). Introductory econometrics: A modern approach (5 ed.). Mason, OH: South-Western, Cengage Learning.

World Bank (2014). Global financial development report 2014: Financial inclusion, Volume 2. Washington, DC: World Bank. 


\section{A. Theoretical Framework: Details (For Online Publication)}

\section{A.1. General Version of the Two-period Model by Kőszegi and Rabin (2009)}

As in Section 2, we assume that an individual has to distribute wealth, $W$, for consumption across two periods such that $W=c_{1}+c_{2}$, where $c_{t}$ denotes consumption in period $t$ for $t=1,2$. As in the main text, we consider the case in which wealth is stochastic and uncertainty is resolved in the second period.

Consumption in the first period (and thus saving) is determined by maximizing the expectation of the sum of instantaneous utilities $u_{t}$ in both periods, where no discounting is assumed, i.e.,

$$
U=u_{1}\left(c_{1}\right)+\mathbb{E}\left[u_{2}\left(c_{2}\right)\right]
$$

As in the simplified version of the model introduced in the main text, individuals are assumed to choose their favorite credible consumption plan before the first period starts (i.e., in period $t=0)$. Credible means that they anticipate whether or not they would be able to stick to the plan, and only consider those plans where they do not see an incentive to deviate from later on. ${ }^{29}$ Favourite means that there are possibly several such credible plans, and the decision-maker chooses his or her preferred one according to the maximization principle. This plan is called preferred personal equilibrium (PPE) by Köszegi and Rabin (2009) and at the time of planning in period $t=0$, it leads to possibly stochastic 'rational beliefs' $F_{0,1}$ and $F_{0,2}$ about consumption in Period 1 and Period 2. Mathematically, these beliefs are simply probability distributions assigning a probability to any possible consumption level. Plans about consumption in period $t$ that are made in the same period (i.e., $F_{t, t}$ ) assign a probability of 1 to the actual consumption level $c_{t}$. When uncertainty is resolved and consumption decisions are implemented, plans are updated and lead to new beliefs.

Instantaneous utility in periods $t=1,2$ is given by

$$
u_{t}=m\left(c_{t}\right)+\sum_{\tau=t}^{2} \gamma_{t, \tau} N\left(F_{t, \tau} \mid F_{t-1, \tau}\right),
$$

where $m(\cdot)$ is consumption utility that is three times differentiable, increasing and strictly concave, and corresponds to a "classical utility function". The 'gain-loss utility', $N\left(F_{t, \tau} \mid F_{t-1, \tau}\right)$, reflects utility gains or losses due to changes in current 'beliefs' $F_{t, \tau}$ compared to former 'beliefs' $F_{t-1, \tau}$ about contemporaneous $(\tau=t)$ and future $(\tau>t)$ consumption. Depending on the

\footnotetext{
${ }^{29}$ Details about how these plans are formed are given in Appendix A.2 or in Köszegi and Rabin (2009).
} 
distance of a period $\tau \geq t$ in the future, the impact of changes in beliefs about consumption in that period via the 'gain-loss utility' differs, which is reflected by weights $\gamma_{t, \tau} \geq 0$ with $\gamma_{t, t}=1$. For simplicity, we use the notation $\gamma_{1,2}=\gamma$. The weight $\gamma_{1,2}=\gamma$ is decisive for an individual to adhere to her plan, i.e., to resist overconsuming in the first period relative to the previously set consumption level, as explained below.

'Gain-loss utility' $N$ compares every percentile of the distributions of consumption according to 'beliefs' $F_{t, \tau}$ and $F_{t-1, \tau}$, using a "universal gain-loss utility function" $\mu$. More specifically, for a possibly discrete distribution $F_{d}, c_{F_{d}}(p / 100)$ is a percentile for $0 \leq p \leq 100$ with $p \in \mathbb{N}$ if $F_{d}\left(c_{F_{d}}(p / 100)\right) \geq p / 100$ and $F_{d}(c)<p / 100$ for all $c<c_{F_{d}}(p / 100)$. Then, gain-loss utility from the change in beliefs from $F_{t-1, \tau}$ to $F_{t, \tau}$ is defined as

$$
N\left(F_{t, \tau} \mid F_{t-1, \tau}\right)=\sum_{p=1}^{100} \mu\left(c_{F_{t, \tau}}(p / 100), c_{F_{t-1, \tau}}(p / 100)\right),
$$

where

$$
\mu(\hat{c}, \tilde{c})= \begin{cases}\eta(m(\hat{c})-m(\tilde{c})) & \text { if } \hat{c} \geq \tilde{c} \\ -\lambda \eta(m(\tilde{c})-m(\hat{c})) & \text { if } \hat{c}<\tilde{c}\end{cases}
$$

for two consumption levels $\hat{c}$ and $\tilde{c}, m$ as defined above and parameters $\eta>0$ and $\lambda>0 .^{30}$

The parameter $\eta>0$ simply scales the difference in consumption utility, and $\lambda>0$ may account for loss-averse $(\lambda>1)$ or gain-seeking $(\lambda<1)$ behavior.

The parameter $\gamma \geq 0$ 'discounts' anticipated future gains or losses in 'gain-loss' utility that affect utility already in period 1. For $\gamma>1 / \lambda$, the anticipated future loss is weighted high enough to prevent the consumer from deviating from the optimal ex-ante plan, i.e., they resist overconsuming; see Proposition 5 in Kôszegi and Rabin (2009). When $\lambda>1$, following Kôszegi and Rabin (2009), we can assume $\gamma<1$. As we allow for gain-seeking behavior, i.e., $\lambda<1$, we leave $\gamma$ unrestricted, to allow for $\gamma>1 / \lambda$. Then, the proof of Proposition 8 in Köszegi and Rabin (2009) holds for $\lambda<1$, although they do not consider this case.

If the agent resists deviating from the plan, instantaneous utility in Period 1 is given by

$$
u_{1}=m\left(c_{1}\right)+N\left(F_{1,1} \mid F_{0,1}\right)+\gamma N\left(F_{1,2} \mid F_{0,2}\right)=m\left(c_{1}\right),
$$

\footnotetext{
${ }^{30}$ This choice of the "gain-loss utility function" fulfills certain desirable characteristics of a reference-dependent utility function for $\lambda>1$; see Köszegi and Rabin (2009), p. 914. In particular, it fulfills "the explicit or implicit assumptions" about the 'value function' by Kahneman and Tversky (1979), as formulated by Bowman et al. (1999).
} 
as beliefs do not change in the first period (i.e., $F_{0, t}=F_{1, t}$ for $t=1,2$ ), since in addition to adherence to the plan, no uncertainty is resolved. In Period 2, utility is given by

$$
u_{2}=m\left(c_{2}\right)+N\left(F_{2,2} \mid F_{1,2}\right) .
$$

With that, the optimization problem can be solved by equalizing the marginal utility of saving and consumption in the first period.

If the agent cannot resist deviating from the ex-ante optimal plan, their PPE specifies a higher consumption level in Period 1 compared to the optimal one; see Proposition 5 in Kôszegi and Rabin (2009).

\section{A.2. Rational Beliefs}

In this Appendix, we explain the intuition behind 'rational beliefs'. We refer to Köszegi and Rabin (2009) for a precise definition.

'Beliefs' are the result of a plan: They "must be rationally based on credible plans for statecontingent behavior". ${ }^{31}$ One concept of what a credible plan could be was termed "preferred personal equilibrium (PPE)' by Köszegi and Rabin (2009) and was used in their text, although they note that other theories of forming beliefs could also be combined with their model. Roughly speaking, a plan is a PPE if it is the preferred "plan among those that are credible". A plan is credible if it maximizes the mathematical expectation of the reference-dependent utility in every period given the beliefs which the plan induced and if continuation plans are consistent. That is: If an individual plans for very low consumption in Period 1 in order to save for Period 2, but would not make the same choice if solving the maximization problem in Period 1 - e.g., because they are present-biased or cannot live with such a low level of consumption -, this would not be a credible plan, and it is not a PPE. Using backwards induction, they would anticipate their behavior in Period 1 and consume more in Period 1 from the beginning until their entire plan is consistent with solutions evolving from a similar maximization process in Period 1. This PPE reflects the idea that individuals anticipate the implications of their plans and only make plans they know they would adhere to them.

\footnotetext{
${ }^{31}$ The most simple example of a state-contingent plan could be: "If things go well, I will spend $x \$$ for consumption in Period 1. If things do not work out well, I will only spent $y \$$ in this period" (where $x>y>0$ ).
} 


\section{A.3. Proofs}

Proof of Proposition 1. This proof follows the rationale of the proof of Proposition 8 in Köszegi and Rabin (2009).

We prove that the derivative of the marginal utility of increasing savings with respect to $\lambda$ is positive. Equivalent to the argument in the proof of Kôszegi and Rabin's Proposition 8, this implies that $d c_{1} / d \lambda<0$ for both $\gamma>1 / \lambda$ and $\gamma \leq 1 / \lambda$, since in the first case, the ex-ante optimal plan involves a lower $c_{1}$ and the person adheres to this plan. In the latter case, a higher marginal utility in Period 2 makes a lower $c_{1}$ become consistent. Furthermore, since, for $\gamma \leq 1 / \lambda$, the chosen $c_{1}$ will be higher than for $\gamma>1 / \lambda$, see Köszegi and Rabin (2009), a lower $c_{1}$ will become consistent, as the agent adheres to the ex-ante optimal plan for a lower $\gamma$.

The derivation of marginal utility of increasing savings is due to Köszegi and Rabin (2009): Let $F$ be the cumulative distribution function of the (mean-zero) random variable $y$. The expected utility in Period 2 is

$$
\begin{aligned}
& \int m\left(c_{2}+s y\right) d F(y)+\iint \mu\left(m\left(c_{2}+s y\right)-m\left(c_{2}+s y^{\prime}\right)\right) d F\left(y^{\prime}\right) d F(y) \\
& =\int m\left(c_{2}+s y\right) d F(y) \\
& \quad-\frac{1}{2} \eta(\lambda-1) \iint m\left(c_{2}+s \max \left\{y, y^{\prime}\right\}\right)-m\left(c_{2}+s \min \left\{y, y^{\prime}\right\}\right) d F\left(y^{\prime}\right) d F(y) .
\end{aligned}
$$

Hence, the derivative of the expected utility in Period 2 with respect to $c_{2}$, i.e., the marginal utility from increasing savings is

$$
\begin{aligned}
& \int m^{\prime}\left(c_{2}+s y\right) d F(y) \\
& \quad+\frac{1}{2} \eta(\lambda-1) \iint m^{\prime}\left(c_{2}+s \min \left\{y, y^{\prime}\right\}\right)-m^{\prime}\left(c_{2}+s \max \left\{y, y^{\prime}\right\}\right) d F\left(y^{\prime}\right) d F(y) .
\end{aligned}
$$

Now, unlike in the proof or Proposition 8 in Köszegi and Rabin (2009), we take the derivative of the expression above with respect to $\lambda$ :

$$
\frac{1}{2} \eta \iint m^{\prime}\left(c_{2}+s \min \left\{y, y^{\prime}\right\}\right)-m^{\prime}\left(c_{2}+s \max \left\{y, y^{\prime}\right\}\right) d F\left(y^{\prime}\right) d F(y) .
$$

This derivative is positive for any strictly concave $m$, any $s>0, \eta>0$, and any non-degenerate random variable $y$. Thus, the marginal utility from increasing savings is an increasing function of $\lambda$. 
Proof of Corollary 1. As in the proof of Proposition 1, the derivative of the marginal utility from increasing savings with respect to $\lambda$ is given by

$$
\frac{1}{2} \eta \iint m^{\prime}\left(c_{2}+s \min \left\{y, y^{\prime}\right\}\right)-m^{\prime}\left(c_{2}+s \max \left\{y, y^{\prime}\right\}\right) d F\left(y^{\prime}\right) d F(y) \text {. }
$$

The derivative of this expression with respect to $s$ evaluated at $s=0$ is

$$
\frac{1}{2} \eta\left(-m^{\prime \prime}\left(c_{2}\right)\right) \iint\left|y^{\prime}-y\right| d F\left(y^{\prime}\right) d F(y)
$$

which is positive for any strictly concave consumption utility function $m, \eta>0$ and any nondegenerate random variable $y$.

\section{B. Data: Details (For Online Publication)}

\section{B.1. Details on the Measures of Loss Aversion}

In this section we describe how we operationalized the different measures of loss aversion with our data, following Abdellaoui et al. (2007).

Kahneman-Tversky (KT) Kahneman and Tversky (1979) define an individual as loss-averse, if for all amounts of money $x$ the utility $\mu$ of receiving this amount is lower than the disutility of losing that same amount, i.e., if $\forall x>0:-\mu(-x)>\mu(x)$. A natural coefficient of loss aversion emerging from this definition is $-\mu(-x) / \mu(x)$ for every elicited amount $x>0$. If $\mu(-x)$ for any of these eight elicited amounts of money $x>0$ was not elicited, it was linearly interpolated. As the coefficient of loss aversion, we took the median of the computed coefficients.

Neilson (N) Neilson (2002) proposes computing the ratio of 'relative steepness', which is the utility value $\mu(x)$ divided by the corresponding $x$-value. This figure incorporates information about steep parts of the utility function at any point of the interval of interest - even in flat regions. If the relative steepness of the utility function over the loss domain is bigger than the one on the gain domain at any point, the individual is classified as loss averse, i.e., $\mu(-x) / x \geq \mu(y) / y, \forall x, y>0$. For this definition, we computed the coefficient of loss aversion as the ratio of the infinum of $\mu(-x) /(-x)$ over the supremum of $\mu(y) / y$.

The remaining definitions rely on the steepness of the utility function as expressed by the derivative of the latter on both domains. 
Wakker-Tversky (WT) Wakker and Tversky (1993) suggest applying the concept of Kahneman and Tversky (1979) to the derivative of utility, i.e., to compare the value of the derivative of the utility function for gains and losses 'point-wise' at certain absolute values: $\mu^{\prime}(-x)>\mu^{\prime}(x), \forall x>0$. At every elicited utility point $x>0$ on the gain domain, the derivative $\mu^{\prime}(x)$ was operationalized as the mean of the two connecting slopes to the left-hand side and to the right-hand side. $\mu^{\prime}(-x)$ was operationalized as the slope of the linearly interpolated utility function at the point $-x$. Similar to the case for the definition by Kahneman and Tversky (1979), a natural coefficient emerging from the definition $\mu^{\prime}(-x)>\mu^{\prime}(x), \forall x>0$, is $\mu^{\prime}(-x) / \mu^{\prime}(x)$ for $x>0$. In this case, we also took the median of the coefficients thus computed.

Bowman (B) Bowman et al. (1999) propose performing this comparison 'domain-wise', that is, $\mu^{\prime}(-x)>\mu^{\prime}(y), \forall x, y>0$. As in the case for the definition by Neilson (2002), the definition $\mu^{\prime}(-x)>\mu^{\prime}(y), \forall x, y>0$ can be transformed into a coefficient of loss aversion by computing $\inf \mu^{\prime}(-x) / \sup \mu^{\prime}(y)$ for $x, y>0$, where the derivatives where operationalized as just described.

Köbberling-Wakker (KW) Finally, Köbberling and Wakker (2005) define an individual as lossaverse if the slope of the utility function on the left-hand side of the reference point is steeper than the slope of the utility function on the right-hand side of the reference point: $\mu^{\prime}\left(0_{-}\right)>$ $\mu^{\prime}\left(0_{+}\right)$. The natural coefficient of loss aversion resulting from this definition, $\mu^{\prime}\left(0_{-}\right) / \mu^{\prime}\left(0_{+}\right)$, was computed as the ratio of slopes connecting 0 with the elicited utility points that are closest to 0 on both domains.

\section{B.2. Parametric Estimation of a Power Utility Function}

General Form for Positive Arguments Usually, the power family is defined for $x>0$ by

$$
m(x)= \begin{cases}x^{b} & \text { for } b>0 \\ \ln (x) & \text { for } b=0 \\ -x^{b} & \text { for } b<0 .\end{cases}
$$

Considering Non-Positive Arguments Since $\ln (x)$ is not defined for $x<0$, the case $b=0$ must be excluded, if negative arguments are of interest. Furthermore, $b<0$ has to be excluded as well, 
if the point $x=0$ is to be considered. ${ }^{32}$ Thus, when allowing for gains and losses, the power family reduces to

$$
m(x)= \begin{cases}-(-x)^{a} & \text { for } a>0, x<0 \\ x^{b} & \text { for } b>0, x \geq 0\end{cases}
$$

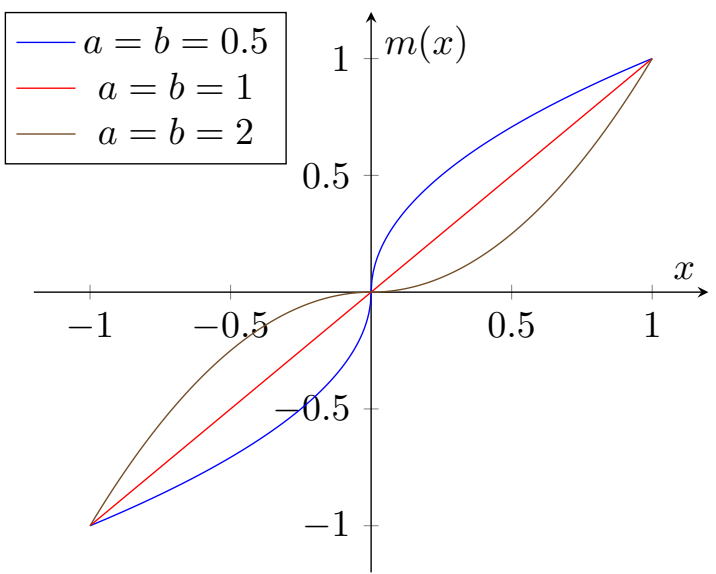

(a) Curvature of the power family for different values of $a$ and $b$.

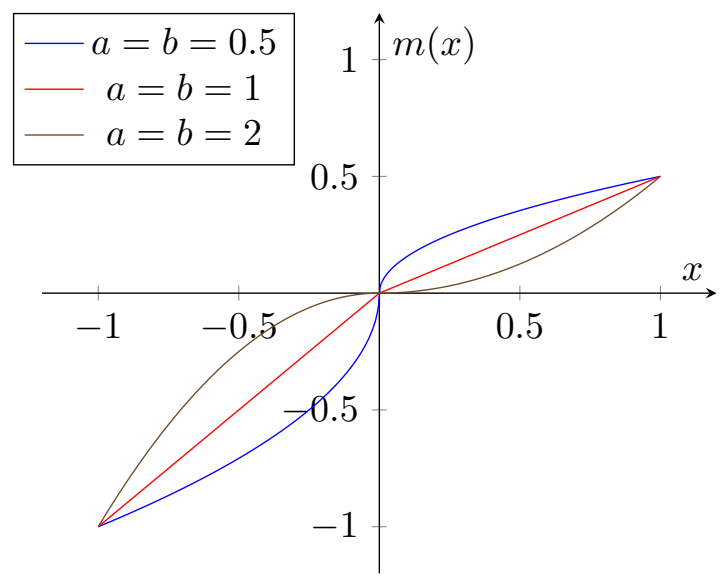

(b) Estimated power utility functions plotted for different values of $a$ and $b$.

Figure 3: Illustration of the Power Family Utility Function with Different Values of $a$ and $b$

Figure 3(a) illustrates the curvature of the power family for different values of $a$ and $b$.

Rescaling Arguments Arguments $x$ of the utility function must be rescaled in order to lie within the interval $[-1,1]$ for all the subjects in the study in order to be able to compare estimated parameters.

Due to the method used, the minimal $x$-value observed is $L_{1}=-5,000,000$. Thus, for losses, we need a transformation $x \mapsto-\frac{x}{L_{1}}$, where $x \in\left[L_{1}, 0\right]$.

For Gains, $G_{0.5}$ is the maximum $x$-value for any individual, we therefore transform $x \mapsto \frac{x}{G_{0.5}}$, where $x \in\left[0, G_{0.5}\right]$.

Rescaling Outputs By the method chosen, we need to have $m\left(L_{1}\right)=-1, m(0)=0$ and $m\left(G_{.5}\right)=$ .5. We check this: For the negative domain, we have

$$
m\left(L_{1}\right)=-\left(\frac{L_{1}}{L_{1}}\right)^{a}=-(1)^{a}=-1,
$$

\footnotetext{
${ }^{32}$ Wakker (2008, p.1336) gives a less technical explanation: "With both positive and negative $x$ present, a negative power $a$ or $b$ generates an infinite distance between gains and losses. Such a phenomenon is not empirically plausible, so that negative $a$ and $b$ should then not be expected to occur."
} 
independent of $a>0$, so there is no need to rescale outputs. However, for the positive domain,

$$
m\left(G_{0.5}\right)=\left(\frac{G_{0.5}}{G_{0.5}}\right)^{b}=1^{b}=1,
$$

independent of $b>0$. Therefore, and also to have estimates comparable for the negative and the positive domain, we rescale $m(x)$ for $x \geq 0$ and set:

$$
m(x)=0.5 \cdot\left(\frac{x}{G_{0.5}}\right)^{b} \quad \text { for } \quad x \geq 0 .
$$

Note that we could also leave the estimation formula untouched and multiply our outcomes by the factor 2 , making them lie within the interval $[0,1]$ instead of $[0, .5]$.

Estimation Equation The final estimation equation is thus

$$
m(x)= \begin{cases}-\left(\frac{x}{L_{1}}\right)^{a} & \text { for } a>0, x<0 \\ 0.5 \cdot\left(\frac{x}{G_{0.5}}\right)^{b} & \text { for } b>0, x \geq 0 .\end{cases}
$$

This equation is illustrated in Figure 3(b).

Curvature In order to classify a utility function as convex or concave based on the estimated values of the parameters $a$ or $b$, we can deduct the curvature of the utility function from Figure 3 for the given values of $a$ and $b$. Analytically, for classifying an individual's utility function, we calculate the second derivative of the estimated utility function.

$$
m^{\prime \prime}(x)= \begin{cases}-\left(\frac{x}{L_{1}}\right)^{a} \cdot \frac{1}{x^{2}} \cdot a(a-1) & \text { for } a>0, x<0 \\ 0.5 \cdot\left(\frac{x}{G_{0.5}}\right)^{b} \cdot \frac{1}{x^{2}} \cdot b(b-1) & \text { for } b>0, x>0,\end{cases}
$$

where $x=0$ has to be excluded from the domain.

We immediately see that for $x>0$,

$$
m^{\prime \prime}(x) \begin{cases}<0 \text { thus } m \text { strictly concave } & \text { if } 0<b<1 \\ =0 \text { thus } m \text { linear } & \text { if } b=1 \\ >0 \text { thus } m \text { strictly convex } & \text { if } b>1,\end{cases}
$$

and for $x<0$ we have

$$
m^{\prime \prime}(x) \begin{cases}<0 \text { thus } m \text { strictly concave } & \text { if } a>1 \\ =0 \text { thus } m \text { linear } & \text { if } a=1 \\ >0 \text { thus } m \text { strictly convex } & \text { if } 0<a<1 .\end{cases}
$$




\section{Results: Details (For Online Publication)}

\section{C.1. Econometric Model}

The outcome variable used in our analysis - savings (in 100,000 COP) - does not include negative values and is therefore a limited dependent variable according to the definition in Wooldridge (2013, Chapter 17). Furthermore, the empirical frequency of zeros in the distribution of the amount of savings in our sample exceeds the frequency of zeros according to any commonly used theoretical distribution in such cases (e.g., the Poisson distribution or the Negative Binomial distribution). This is to be expected, since not everybody actually engages in saving. Thus, the outcome variable is a so-called Corner Solution Response. ${ }^{33}$

The distribution of the value of saving in our sample is skewed, and values are reported repeatedly and are usually divisible by 100,000 COP. Therefore, we should assume a discrete rather than a continuous dependent variable. Given these characteristics of the outcome variable, we apply a Negative Binomial Hurdle model to study the relationship between income risk, loss aversion, and savings. The Poisson Hurdle model is nested in the Negative Binomial Hurdle model we fit and differences between the log-likelihoods of both models mostly exceed 100 by far. This indicates that a likelihood ratio test (conservatively assuming the test statistic to follow a chi-square distribution with one degree of freedom) would reject the hypothesis of no overdispersion.

This model is a so-called two-part model, where the probability of engaging in savings and the amount of savings is estimated separately by different models. For the Hurdle models applied here, the likelihood of both equations can be calculated separately. Using a logit-model, the probability 'that the hurdle is passed' and that a person engages in savings is estimated. The second model estimates the amount of savings once the hurdle is passed, using a Truncated Negative Binomial model. In Appendix C.2, we discuss alternative models and their suitability in this context.

\footnotetext{
${ }^{33}$ The options to deny the response or to indicate that they did not know about the amount of savings were allowed and treated separately. Four respondents denied answering and five respondents did not know the amount of savings they held at the time of the interview. Together, this corresponds to about $1 \%$ of the respondents whose savings amount we could not observe. These cases were excluded from the analysis.
} 
Following Grogger and Carson (1991), we compute marginal effects of loss aversion and income risk on the predicted amount of unconditional savings using the estimates resulting from fitting Model 3 with a Negative Binomial Hurdle model. Denoting savings for individual $i$ with $Y_{i}$, the overall marginal effect of $X_{i h}$, i.e., of covariate $h$ for individual $i$, on his or her predicted savings can be computed as

$$
\frac{\partial \mathbb{E}\left(Y_{i} \mid X_{i}\right)}{\partial X_{i h}}=\frac{\partial}{\partial X_{i h}}\left[\mathbb{E}\left(Y_{i} \mid X_{i}, Y_{i}>0\right)\right][1-F(0)]+\mathbb{E}\left(Y_{i} \mid X_{i}, Y_{i}>0\right) \frac{\partial}{\partial X_{i h}}[1-F(0)],
$$

where $1-F(0)$ is the share of the population for which we observe $Y_{i}>0$. This means the overall effect can be decomposed into two effects: The effect on those who are saving, weighted by the probability of saving, plus the effect on the proportion that 'passes the hurdle' and is saving, weighted by the mean amount of savings in the saving population. We compute marginal effects using mean values of covariates, unless otherwise indicated.

\section{C.2. Discussion: Model Choice}

In this part, we briefly discuss alternatives to the model chosen and assess their appropriateness in the setting of this paper.

Usually, OLS regression is a suitable starting point for modelling empirical relationships. However, a large share of the non-savers with zero COP of savings could mask relationships observed for the fraction of participants that actually saves. It seems appropriate to take the large share of the non-savers observed in our data into account when selecting a suitable model.

A Tobit model is frequently used in similar situations. Here, it is not suitable. A central assumption of the Tobit model is that the process determining participation is the same as the process determining the amount of saving. The signs of the coefficients of the independent variables in Table 4 differ in the two equations where many are significantly different from zero, showing that this assumption is violated. Second, normality and homoscedasticity of the dependent variable model are prerequisites for using a Tobit model. In contrast to OLS, where departures from these assumptions still lead to unbiased and consistent estimates, it is less clear how sensitive the Tobit model is to departures from these assumptions. The empirical distribution of the outcome variable we observe in our data is discrete. This observed empirical distribution is a rather bad approximation of any continuous probability distribution, so the assumption of normality is not likely to hold. 
More flexible models for corner solution responses that can model the participation process and the savings process separately are - in addition to the Hurdle model applied in this study - so-called inflated models. For example, the Zero-Inflated Poisson model or the Zero-Inflated Negative Binomial model for the case of a discrete dependent variable.

Zero-inflated models rely on the assumption that a zero COP value of savings can be the result of two cases: In the first case, an individual would decide to save and then chooses a saving amount of zero. In the second case, an individual would decide not to save at all. We believe that the first case is rather unrealistic, since we did not ask for changes in savings in a given limited time, but rather look at the stock of savings. We therefore conclude that these models are not appropriate in our setting.

It is noteworthy that the excess zeros in the distribution of the outcome variable are not a problem of data observability, where models for censored data or sample correction models (e.g., the Heckman model) would be adequate. Only for around 1 percent of the participants are data actually missing, and these cases were excluded.

When only focusing on the positive amount of savings, no special care is needed to account for excessive zeros in the distribution of the outcome variable. In such cases, a traditional OLS model could be applied, or a log OLS model, if we expect the relationship to be proportional to the response.

Given the discrete character of the outcome variable, and its heavily non-symmetric empirical distribution, a model that accounts for this characteristic should be applied, such as the ZeroTruncated Poisson or the Zero-Truncated Negative Binomial model. The latter is the second part of the two-part model we apply, the Negative Binomial Hurdle model. Thus, if not accounting for excess zeroes, we would model conditional savings in the same way that we do in this study, while accounting for a large proportion of non-savers.

\section{Further Results and Robustness (For Online Publication)}




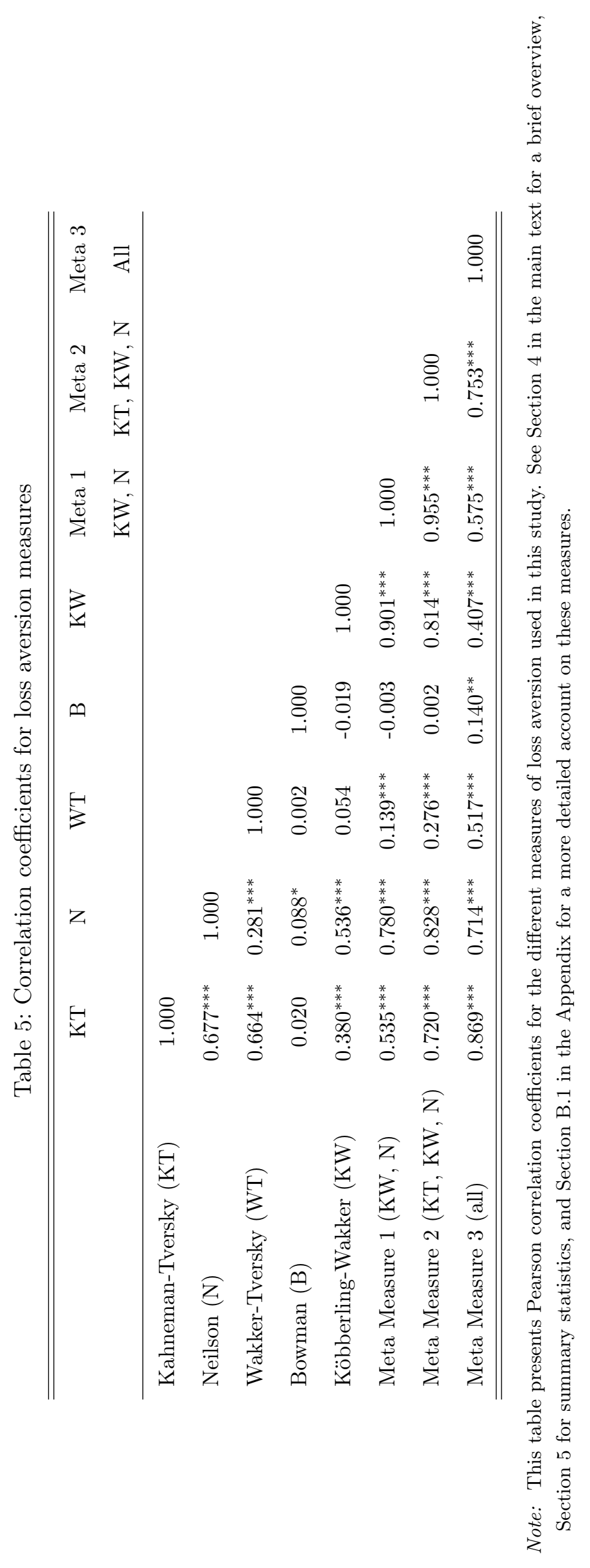



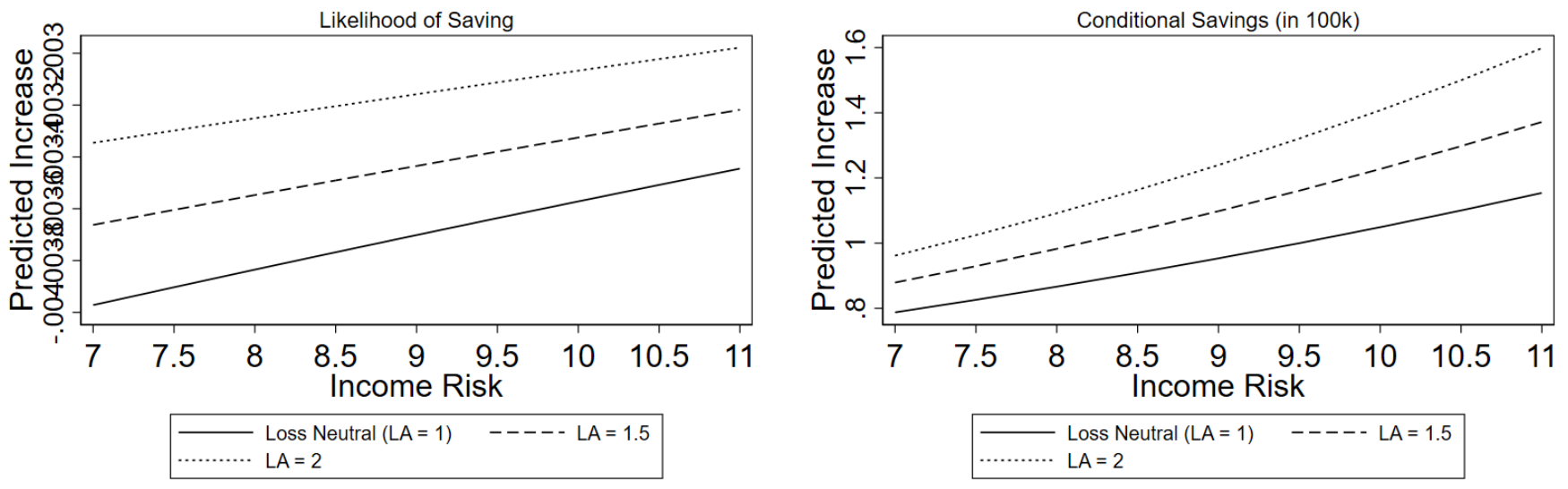

(a) Measure of Income Risk: Unemployment Rate (DANE)
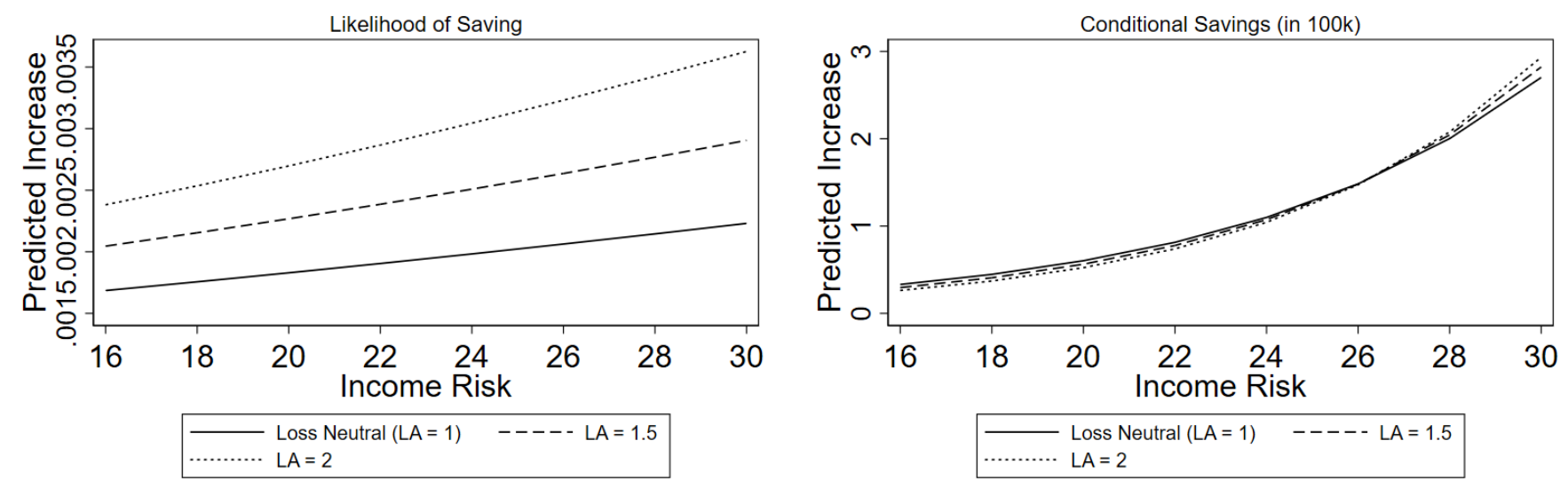

(b) Measure of Income Risk: Unemployment Risk (Survey)

Figure 4: Conditional Marginal Effect of Income Risk on the Predicted Likelihood to Save (left) and on Predicted Conditional Savings (right) for Different Degrees of Loss Aversion

Note: Mean values of the covariates used for prediction. Estimates for calculating the marginal effects result from fitting Model 3; see Table 4 for the corresponding coefficients. Income Risk is expressed in percent and the predicted increase in conditional savings in 100,000 COP. 

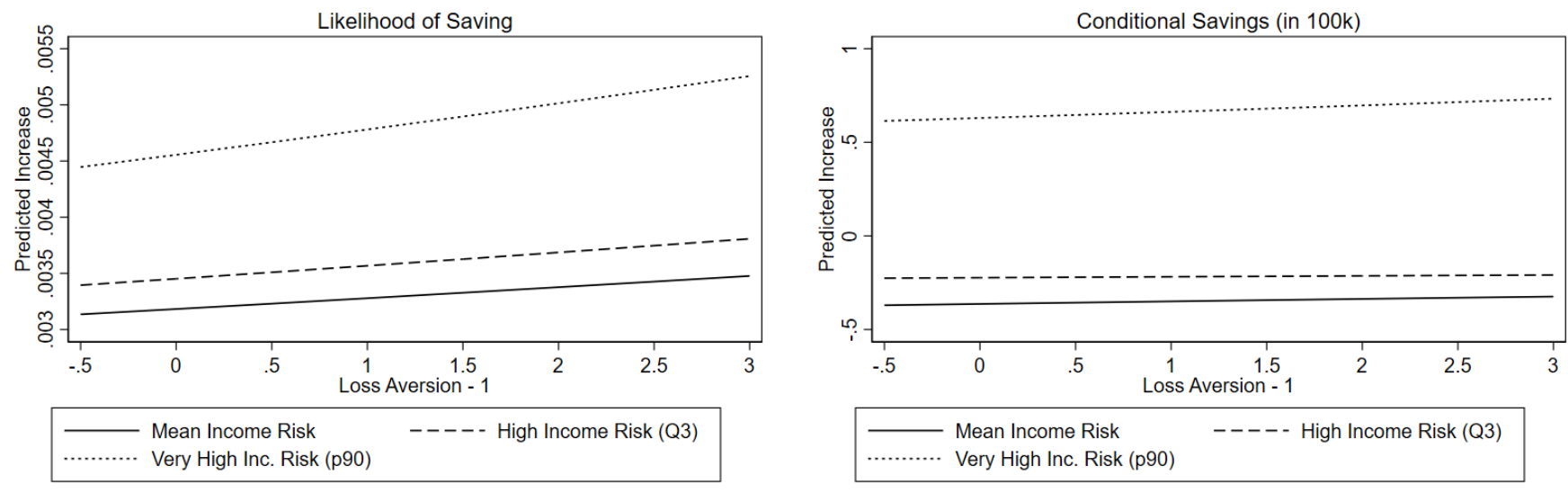

(a) Measure of Income Risk: Unemployment Rate (DANE)
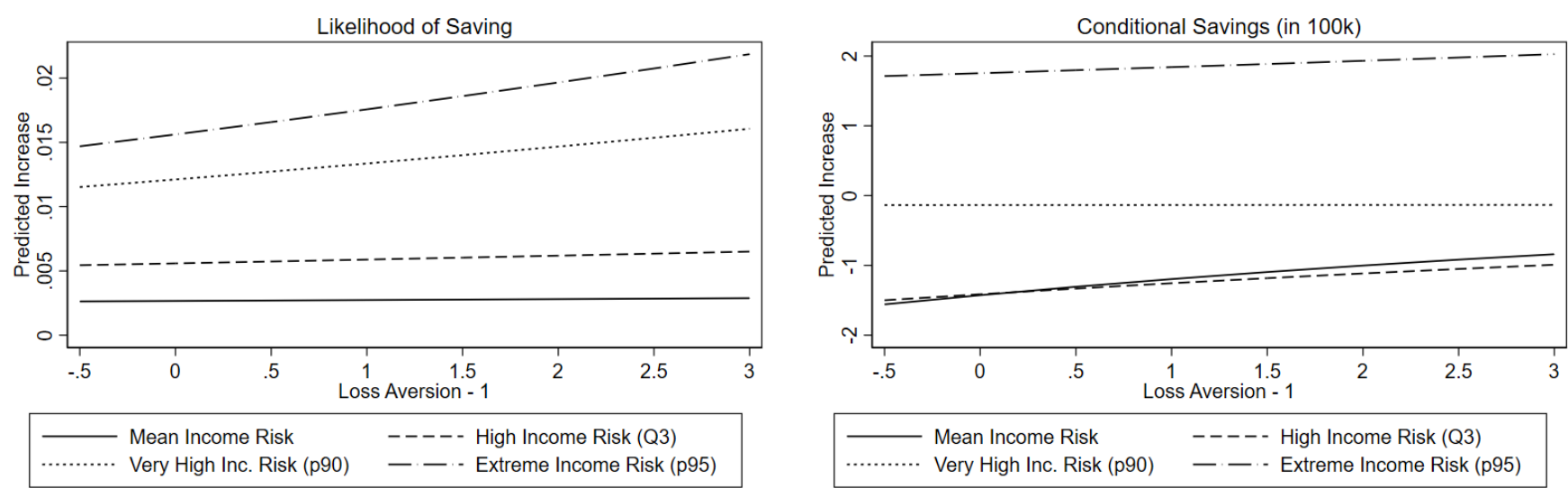

(b) Measure of Income Risk: Unemployment Risk (Survey)

Figure 5: Conditional Marginal Effect of Loss Aversion on the Predicted Likelihood to Save (left) and on

Predicted Conditional Savings (right) for Different Levels of Income Risk

Note: Mean values of the covariates used for prediction. Estimates for calculating the marginal effects result from fitting Model 3; see Table 4 for the corresponding coefficients. The predicted increase in conditional savings is expressed in 100,000 COP. 
Table 6: Results from Estimating Model 2 Using a Negative Binomial Hurdle Model, Income Risk

(Unemployment Rate provided by DANE), and Different Meta-Measures of Loss Aversion

\begin{tabular}{|c|c|c|c|c|c|c|}
\hline & \multicolumn{3}{|c|}{$\begin{array}{c}\text { Loss Aversion } \\
2 \text { Measures } \\
(\mathrm{KW}, \mathrm{N})\end{array}$} & \multicolumn{2}{|c|}{$\begin{array}{c}\text { Loss Aversion } \\
3 \text { Measures } \\
(\mathrm{KW}, \mathrm{N}, \mathrm{KT})\end{array}$} & \multirow{2}{*}{$\begin{array}{c}\text { Loss Aversion } \\
5 \text { Measures } \\
(\text { All }) \\
(6)\end{array}$} \\
\hline & (1) & (2) & (3) & (4) & (5) & \\
\hline \multicolumn{7}{|l|}{ Likelihood of Saving } \\
\hline \multirow[t]{2}{*}{ Loss Aversion } & 0.041 & 0.041 & 0.028 & $0.078^{*}$ & 0.061 & 0.267 \\
\hline & $(-1.68)$ & $(-1.65)$ & $(-1.00)$ & $(-2.00)$ & $(-1.42)$ & $(-1.93)$ \\
\hline \multirow[t]{2}{*}{ Income Risk (DANE) } & -0.068 & -0.055 & -0.028 & -0.053 & -0.028 & -0.015 \\
\hline & $(0.66)$ & $(0.52)$ & $(0.26)$ & $(0.51)$ & $(0.26)$ & $(0.14)$ \\
\hline \multicolumn{7}{|l|}{ Amount of Savings } \\
\hline \multirow[t]{2}{*}{ Loss Aversion } & $0.058^{*}$ & $0.065^{* *}$ & $0.088^{* * *}$ & $0.089^{* * *}$ & $0.103^{* * *}$ & $0.247^{*}$ \\
\hline & $(2.55)$ & $(2.84)$ & $(3.62)$ & $(3.44)$ & $(3.43)$ & $(2.09)$ \\
\hline \multirow[t]{2}{*}{ Income Risk (DANE) } & 0.199 & 0.082 & -0.032 & 0.081 & -0.026 & -0.051 \\
\hline & $(1.36)$ & $(0.48)$ & $(-0.18)$ & $(0.48)$ & $(-0.15)$ & $(-0.28)$ \\
\hline AIC & 1244 & 1140 & 1019 & 1138 & 1019 & 1021 \\
\hline Controls & 25 & 25 & 25 & 25 & 25 & 25 \\
\hline Region & Yes & Yes & Yes & Yes & Yes & Yes \\
\hline Occupation & Yes & Yes & Yes & Yes & Yes & Yes \\
\hline Observations & 640 & 579 & 509 & 579 & 509 & 509 \\
\hline
\end{tabular}

${ }^{\star} \mathrm{p}<0.1,{ }^{\star \star} \mathrm{p}<0.05,{ }^{\star \star \star} \mathrm{p}<0.01$. t-values in parentheses.

Note: The dependent variable is the sum of self-reported savings data in various savings devices; see Section 4 . In this Negative Binomial Hurdle model, the participation equation estimates the likelihood to engage in savings, while the second equation estimates conditional savings - the amount of savings, given that a person is saving. Loss aversion is measured by continuous and experimentally elicited meta-measures. The meta-measure comprising two measures of loss aversion is the geometric mean of loss aversion coefficients according to the definitions of loss aversion by Neilson (2002) and Köbberling and Wakker (2005). The measure including three measures is the geometric mean of the former two loss aversion coefficients and, in addition, the one building on the definition of loss aversion by Kahneman and Tversky (1979). Finally, for the last measure, the coefficients based on definitions by Bowman et al. (1999) and Wakker and Tversky (1993) are also included. For more details on the applied measures of loss aversion, see Appendix B.1. Column 2 shows the results when restricting the sample to those for which the meta-measure combining three measures of loss aversion is available, and columns 3 and 5 show the results for similarly restricted samples, in order to be able to draw comparisons between the different meta-measures of loss aversion. We control for variables listed in Tables 2 and 3. Furthermore, we control for regional and occupational sectors at localidad level, as well as for the working sectors according to the ISIC classification of economic activities. We account for potential heteroskedasticity by using robust standard errors. 
Table 7: Results from Estimating Model 2 Using a Negative Binomial Hurdle Model, Income Risk

(Unemployment Risk, aggr. Survey Measure), and Different Meta-Measures of Loss Aversion

\begin{tabular}{|c|c|c|c|c|c|c|}
\hline & \multicolumn{3}{|c|}{$\begin{array}{c}\text { Loss Aversion } \\
2 \text { Measures } \\
(\mathrm{KW}, \mathrm{N})\end{array}$} & \multicolumn{2}{|c|}{$\begin{array}{c}\text { Loss Aversion } \\
3 \text { Measures } \\
(\mathrm{KW}, \mathrm{N}, \mathrm{KT})\end{array}$} & \multirow{2}{*}{$\begin{array}{c}\text { Loss Aversion } \\
5 \text { Measures } \\
\text { (All) } \\
(6)\end{array}$} \\
\hline & (1) & $(2)$ & (3) & (4) & (5) & \\
\hline \multicolumn{7}{|l|}{ Likelihood of Saving } \\
\hline \multirow[t]{2}{*}{ Loss Aversion } & 0.042 & 0.043 & 0.030 & $0.079^{*}$ & 0.063 & $0.266^{*}$ \\
\hline & $(-1.74)$ & $(-1.78)$ & $(-1.16)$ & $(-2.16)$ & $(-1.61)$ & $(-2.05)$ \\
\hline \multirow[t]{2}{*}{ Income Risk (Survey) } & 0.027 & 0.055 & 0.068 & 0.055 & 0.069 & 0.067 \\
\hline & $(-0.71)$ & $(-1.29)$ & $(-1.62)$ & $(-1.30)$ & $(-1.64)$ & $(-1.59)$ \\
\hline \multicolumn{7}{|l|}{ Amount of Savings } \\
\hline \multirow[t]{2}{*}{ Loss Aversion } & $0.062^{* *}$ & $0.068^{* *}$ & $0.085^{* * *}$ & $0.092^{* * *}$ & $0.100^{* *}$ & 0.228 \\
\hline & $(2.61)$ & $(2.99)$ & $(3.48)$ & $(3.61)$ & $(3.29)$ & $(1.79)$ \\
\hline \multirow[t]{2}{*}{ Income Risk (Survey) } & $0.145^{* *}$ & $0.165^{* * *}$ & $0.136^{*}$ & $0.166^{* * *}$ & $0.138^{*}$ & $0.139^{*}$ \\
\hline & $(2.90)$ & $(3.54)$ & $(2.17)$ & $(3.58)$ & $(2.18)$ & $(2.06)$ \\
\hline AIC & 1240 & 1133 & 1016 & 1130 & 1015 & 1018 \\
\hline Controls & 25 & 25 & 25 & 25 & 25 & 25 \\
\hline Region & Yes & Yes & Yes & Yes & Yes & Yes \\
\hline Occupation & Yes & Yes & Yes & Yes & Yes & Yes \\
\hline Observations & 640 & 579 & 509 & 579 & 509 & 509 \\
\hline
\end{tabular}

${ }^{\star} \mathrm{p}<0.1,{ }^{\star \star} \mathrm{p}<0.05,{ }^{\star \star \star} \mathrm{p}<0.01$. t-values in parentheses.

Note: The dependent variable is the sum of self-reported savings data in various savings devices; see Section 4 . In this Negative Binomial Hurdle model, the participation equation estimates the likelihood to engage in savings, while the second equation estimates conditional savings - the amount of savings, given that a person is saving. Loss aversion is measured by continuous and experimentally elicited meta-measures. The meta-measure comprising two measures of loss aversion is the geometric mean of loss aversion coefficients according to the definitions of loss aversion by Neilson (2002) and Köbberling and Wakker (2005). The measure including three measures is the geometric mean of the former two loss aversion coefficients and, in addition, the one building on the definition of loss aversion by Kahneman and Tversky (1979). Finally, for the last measure, the coefficients based on definitions by Bowman et al. (1999) and Wakker and Tversky (1993) are also included. For more details on the applied measures of loss aversion, see Appendix B.1. Column 2 shows the results when restricting the sample to those for which the meta-measure combining three measures of loss aversion is available, and columns 3 and 5 show the results for similarly restricted samples, in order to be able to draw comparisons between the different meta-measures of loss aversion. We control for variables listed in Tables 2 and 3. Furthermore, we control for regional and occupational sectors at localidad level, as well as for the working sectors according to the ISIC classification of economic activities. We account for potential heteroskedasticity by using robust standard errors. 
Table 8: Results from Estimating Model 3 Using a Negative Binomial Hurdle Model and Different Meta-Measures of Loss Aversion

\begin{tabular}{|c|c|c|c|c|c|c|}
\hline & \multicolumn{3}{|c|}{ Regional Unemployment Rate } & \multicolumn{3}{|c|}{ Regional Unemployment Risk } \\
\hline & $\begin{array}{c}\text { Measure } 1 \\
(\mathrm{KW}, \mathrm{N})\end{array}$ & $\begin{array}{c}\text { Measure } 2 \\
(\mathrm{KT}, \mathrm{KW}, \mathrm{N})\end{array}$ & $\begin{array}{c}\text { Measure } 3 \\
\text { (All) }\end{array}$ & $\begin{array}{c}\text { Measure } 1 \\
(\mathrm{KW}, \mathrm{N})\end{array}$ & $\begin{array}{c}\text { Measure } 2 \\
(\mathrm{KT}, \mathrm{KW}, \mathrm{N})\end{array}$ & $\begin{array}{c}\text { Measure } 3 \\
\text { (All) }\end{array}$ \\
\hline \multicolumn{7}{|l|}{ Likelihood of Saving } \\
\hline Loss Aversion & 0.00774 & 0.0120 & 0.0609 & 0.0121 & $0.0174^{\star}$ & $0.0459^{\star \star}$ \\
\hline$\times$ Income Risk & $(0.83)$ & $(0.82)$ & $(0.86)$ & $(1.55)$ & $(1.79)$ & $(2.48)$ \\
\hline \multirow[t]{2}{*}{ Loss Aversion } & $0.0353^{\star}$ & $0.0698^{\star \star}$ & $0.273^{\star \star}$ & 0.0319 & 0.0635 & 0.131 \\
\hline & $(1.76)$ & $(2.12)$ & $(2.00)$ & $(1.15)$ & $(1.43)$ & $(0.80)$ \\
\hline \multirow[t]{2}{*}{ Income Risk } & -0.0410 & -0.0316 & 0.0336 & 0.0253 & 0.0547 & $0.0959^{\star \star}$ \\
\hline & $(-0.55)$ & $(-0.40)$ & $(0.36)$ & $(0.66)$ & $(1.29)$ & $(2.23)$ \\
\hline \multicolumn{7}{|l|}{ Amount of Savings } \\
\hline Loss Aversion & $0.0315^{\star \star}$ & 0.0315 & 0.0611 & $0.0224^{\star \star \star}$ & $0.0199^{\star \star}$ & 0.0465 \\
\hline × Income Risk & $(2.12)$ & $(1.22)$ & $(0.78)$ & $(4.47)$ & $(2.21)$ & $(1.54)$ \\
\hline \multirow[t]{2}{*}{ Loss Aversion } & -0.0382 & -0.0204 & 0.0893 & $-0.177^{\star \star \star}$ & -0.129 & -0.169 \\
\hline & $(-0.88)$ & $(-0.26)$ & $(0.58)$ & $(-3.25)$ & $(-1.22)$ & $(-0.64)$ \\
\hline \multirow[t]{2}{*}{ Income Risk } & 0.0955 & 0.0573 & 0.108 & $0.150^{\star \star \star}$ & $0.167^{\star \star \star}$ & $0.186^{\star \star \star}$ \\
\hline & $(1.12)$ & $(0.68)$ & $(0.75)$ & $(3.35)$ & $(3.69)$ & $(2.95)$ \\
\hline $\mathrm{AIC}$ & 1240 & 1137 & 1023 & 1225 & 1125 & 1015 \\
\hline Controls & 25 & 25 & 25 & 25 & 25 & 25 \\
\hline Region & No & No & No & Yes & Yes & Yes \\
\hline Occupation & Yes & Yes & Yes & Yes & Yes & Yes \\
\hline Observations & 640 & 579 & 509 & 640 & 579 & 509 \\
\hline
\end{tabular}

${ }^{\star} \mathrm{p}<0.1,{ }^{\star \star} \mathrm{p}<0.05,{ }^{\star \star \star} \mathrm{p}<0.01$. t-values in parentheses.

Note: The dependent variable is the sum of self-reported savings data in various savings devices; see Section 4 . In this Negative Binomial Hurdle model, the participation equation estimates the likelihood to engage in savings, while the second equation estimates conditional savings - the amount of savings, given that a person is saving. Loss aversion is measured by continuous and experimentally elicited meta-measures. The meta-measure comprising two measures of loss aversion is the geometric mean of loss aversion coefficients according to the definitions of loss aversion by Neilson (2002) and Köbberling and Wakker (2005) (Measure 1). The measure including three measures is the geometric mean of the former two loss aversion coefficients and, in addition, the one building on the definition of loss aversion by Kahneman and Tversky (1979) (Measure 2). Finally, for the last measure, the coefficients based on definitions by Bowman et al. (1999) and Wakker and Tversky (1993) are also included (Measure 3). The coefficients of loss aversion are centered at 1; for more details on the applied measures of loss aversion, see Appendix B.1. Income risk is centered at the mean and is based on different measures, partly building on secondary data; see Section 4 for details. We control for variables listed in Tables 2 and 3. Furthermore, we control for regional and occupational sectors at localidad level as well as for the working sectors according to the ISIC classification of economic activities, if indicated. We account for potential heteroskedasticity by using robust standard errors. 